Research Article

\title{
Coupling Analysis and Cross-Feedback Control of Three-Axis Inertially Stabilized Platform with an Active Magnetic Bearing System
}

\author{
Tong Wen, ${ }^{1,2}$ Biao Xiang $\mathbb{C}^{3}{ }^{3}$ and Waion Wong ${ }^{3}$ \\ ${ }^{1}$ School of Instrument Science and Optoelectronics Engineering, Beihang University, Beijing 100191, China \\ ${ }^{2}$ Ningbo Institute of Technology, Beihang University, Ningbo, Zhejiang 31500, China \\ ${ }^{3}$ Department of Mechanical Engineering, The Hong Kong Polytechnic University, Kowloon, China
}

Correspondence should be addressed to Biao Xiang; thomas.biao@gmail.com

Received 18 December 2019; Revised 17 June 2020; Accepted 6 July 2020; Published 22 July 2020

Academic Editor: Fabio Minghini

Copyright (c) 2020 Tong Wen et al. This is an open access article distributed under the Creative Commons Attribution License, which permits unrestricted use, distribution, and reproduction in any medium, provided the original work is properly cited.

An active magnetic bearing (AMB) system is used to suspend the yaw gimbal of three-axis inertially stabilized platform (ISP) to minimize the friction. The dynamic functions of three gimbals in ISP are developed. The base coupling at dynamic base plate is stronger than that at static base plate, and the gimbal coupling among three gimbals increases with the number of unlocked gimbals. Therefore, a cross-feedback control scheme is designed to minimize the base coupling and the gimbal coupling, and then the multi-input multioutput system of three-axis ISP with coupling terms is simplified into three decoupled single-input singleoutput systems. Experimental results verify that the yaw gimbal suspended by AMB system has better vibration isolation ability than the roll gimbal supported by mechanical bearing, and the gimbal coupling and the base coupling are effectively suppressed by the cross-feedback control scheme.

\section{Introduction}

The inertially stabilized platform (ISP) is widely used in the remote sensing and imaging system on the airborne platform [1-3] and the ship-based platform [4] to track the line of sight. It could keep the stability of remote sensing and imaging payloads by connecting with the flight carrier, so the external vibration disturbances such as the random vibration of flight carrier would be isolated. The remote sensing and imaging payloads are commonly installed on the yaw gimbal of three-axis ISP, and the stability of remote sensing and imaging system is therefore directly affected by the attitude stabilization precision of yaw gimbal $[5,6]$. In the normal three-axis ISP, the roll, pitch, and yaw gimbals are supported by mechanical bearings and gears [7]. It is possible that the friction of the mechanical bearing and gear affects the attitude stabilization precision of supported gimbals [8-11]. In addition, the disturbances could be transferred from the pitch and roll gimbals to the yaw gimbal such that the attitude stabilization precision of yaw gimbal is reduced [12-14]. Therefore, in order to suppress the vibration acting on yaw gimbal, an active magnetic bearing (AMB) [15-17] system was designed for suspending the yaw gimbal in three-axis ISP. Since the AMB system provides a contactless suspension to yaw gimbal, the vibration disturbances from other gimbals could be effectively isolated, and the friction between levitated gimbal and suspension elements would be minimized [18]. Moreover, the displacement of yaw gimbal is controllable by regulating the winding current of AMB system based on displacement feedback [19-23], and then the vibration isolation could be realized with the active controllability of an AMB system [24].

Although friction and vibration transmission of yaw gimbal are suppressed by the AMB system, the couplings among three gimbals in three-axis ISP still affect the attitude stabilization precision of yaw gimbal. The coupling effect among three gimbals and base plate was analyzed in [25], 
simulation results showed that attitude stabilization precisions of three gimbals were affected by the coupling effect among three gimbals and the base plate when the error of axial angular velocity increased from $0.05 \mathrm{rad} / \mathrm{s}$ to $0.3 \mathrm{rad} / \mathrm{s}$. A decoupling control method [26] was used in a differential cable driving ISP to minimize the coupling effect among three gimbals and the base plate, and the control precision was improved by suppressing the coupling terms. Another decoupling control method based on the feed-forward compensation was used to control the ISP [27]; the peak value of pitch gimbal's rotational angle was reduced from $0.6^{\circ}$ to $0.2^{\circ}$. In addition, the adaptive decoupling control based on neural network was used to improve the control performances of three gimbals in a three-axis ISP [28]; the track error of azimuth gimbal was reduced by $80 \%$. The sliding mode control based on the extended state observer in $[29,30]$ was used to suppress various types of disturbances in the ISP. Simulation result showed that the unknown state and the lumped uncertainty of gimbal could be accurately estimated, and the maximum deflection of yaw gimbal was declined from $0.5332^{\circ}$ to $0.0811^{\circ}$. In literature [31], a compound control method based on model reference adaptive control and proportional-integral-derivative (PID) control was proposed to improve the tracking precision and the robustness of ISP system. It could suppress the nonlinear unbalance torque caused by the time-varying mass, and the position precision of yaw gimbal was improved by $50 \%$.

Even though the abovementioned control methods such as the disturbance observer [32], robust control [33], and sliding mode control $[34,35]$ were useful to improve the control precisions of ISP gimbals, the equations of motion of three gimbals were simplified as a decoupled system by neglecting coupling terms among three gimbals and the base plate. Moreover, the coupling effect among three gimbals and the base plate was not verified experimentally, and its influences on the attitude stabilization precision of each gimbal were not tested. More importantly, the coupling effect was not studied in a three-axis ISP with an AMB system integrating the control schemes of torque motors and AMB system.

Above all, the original works of this article are focused on three parts to further improve the attitude stabilization precision of yaw gimbal, and the novelties of this article are listed as follows:

(1) A novel structure of yaw gimbal with an AMB system integrating the axial and radial motion is firstly designed to minimize the friction and vibration transmission, and dynamic functions of three gimbals with coupling terms are developed.

(2) The influences of coupling terms among three gimbals and the base plate are firstly quantified in the experiment, and the mathematic models of coupling terms are originally developed. It proves that the base coupling with dynamic base plate is greater than that with static base plate, and the gimbal coupling among three gimbals increases with the number of unlocked gimbals.
(3) The cross-feedback control scheme is proposed to improve the attitude stabilization precision of yaw gimbal with dynamic disturbances.

Consequently, the AMB system is used as a novel suspension system in three-axis ISP, and this structure broadens the application scope of AMB system and improves attitude stabilization precision of yaw gimbal.

This article is organized as follows. In Section 2, the structure of three-axis ISP with an AMB system is introduced, and equations of motion of three gimbals are developed, and then the coupling effects among three gimbals and the base plate are analyzed. In Section 3, the crossfeedback control scheme with angular displacements of three gimbals is used to suppress the coupling effect acting on the yaw gimbal, and the experiments are conducted to verify the effectiveness of proposed cross-feedback control scheme.

\section{Three-Axis ISP with an AMB System}

2.1. Structure of Three-Axis ISP with an AMB System. The mechanical structure of three-axis ISP with an AMB system is illustrated in Figure 1. The three-axis ISP consists of three rotational gimbals (yaw, pitch, and roll gimbals), an AMB system, and a base plate. The yaw gimbal (the innermost gimbal) supports the sensing and imaging payloads, and it rotates about $z_{y}$ axis as illustrated in Figure 2(c). As shown in Figure 1(b), the rotor part of AMB system is located on the yaw gimbal while the stator part is mounted on the pitch gimbal. The AMB system generates magnetic forces to suspend the yaw gimbal at the radial and axial equilibrium positions, and the position of yaw gimbal is controllable by regulating the winding current of AMB system based on the displacement feedback. The pitch gimbal connects to the roll gimbal by mechanical bearing, and it locates outside of yaw gimbal. The torque motor of pitch gimbal controls its rotation about $x_{p}$ axis in Figure 2(b). As the external gimbal, the roll gimbal locates outside of pitch gimbal, and the torque motor on roll gimbal controls its rotation about $y_{r}$ axis as shown in Figure 2(a). The bracket is used to connect the roll gimbal with the base plate, and the base plate connects three-axis ISP with the swaying platform or flight carriers.

\subsection{Coordinate System of Three-Axis ISP with an AMB System.} The coordinate systems of three gimbals in the ISP are illuminated in Figure 2. $O X_{b} Y_{b} Z_{b}$ is the coordinate system of base plate. $O X_{r} Y_{r} Z_{r}$ is the coordinate system of roll gimbal. $O X_{p} Y_{p} Z_{p}$ is the coordinate system of pitch gimbal, and $O X_{y} y Y_{y} Z_{y}$ is the coordinate system of yaw gimbal. $\theta_{r y}, \theta_{p x}$, and $\theta_{y z}$ are rotational angles of three gimbals, respectively. $\dot{\theta}_{r y}, \dot{\theta}_{p x}$, and $\dot{\theta}_{y z}$ are relative angular rates of three gimbals, respectively. Three torque motors on pitch, roll, and yaw gimbals control the rotations of three-axis ISP about $X_{p}, Y_{r}$, and $Z_{y}$ axes, respectively. Therefore, the rotations of threeaxis ISP about three pivot axes could be expressed in terms of angular rates of three gimbals. 


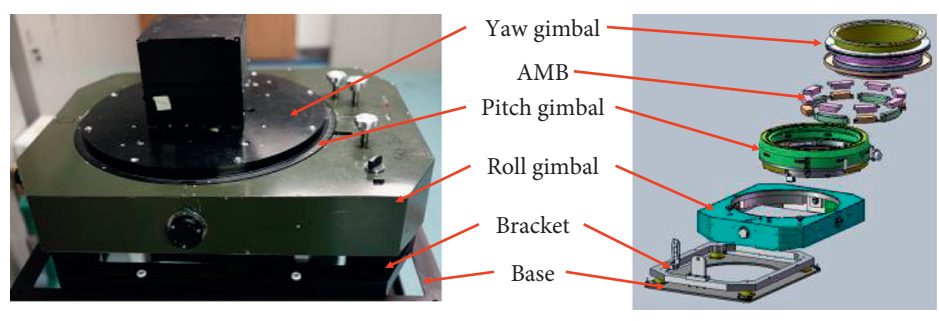

(a)

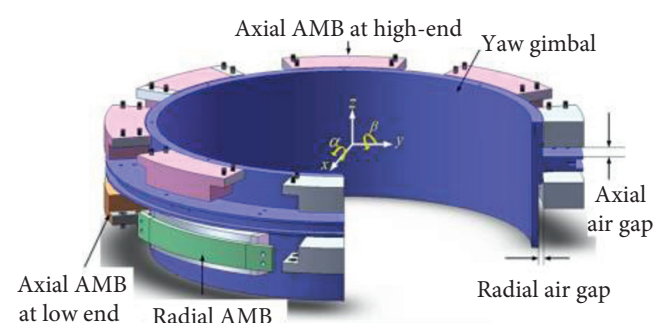

(b)

Figure 1: (a) Configuration of the three-axis ISP. (b) The structure of AMB system.

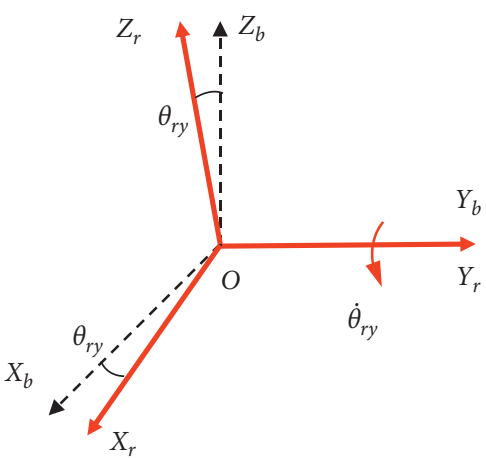

(a)

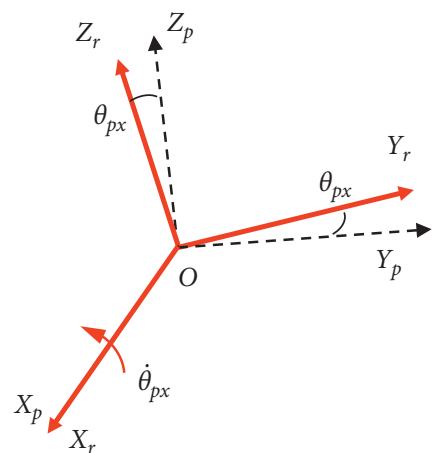

(b)

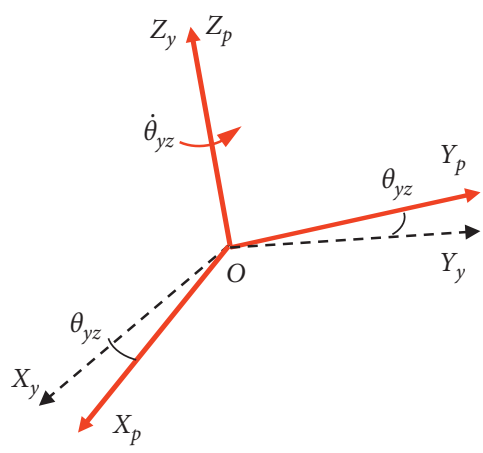

(c)

FIgURE 2: Coordinate systems of (a) roll gimbal, (b) pitch gimbal, and (c) yaw gimbal in ISP.

The angular rates of roll gimbal around three axes could be derived and written as

$$
\left[\begin{array}{c}
\omega_{r x} \\
\omega_{r y} \\
\omega_{r z}
\end{array}\right]=C_{b}^{r}\left[\begin{array}{c}
\omega_{b x} \\
\omega_{b y} \\
\omega_{b z}
\end{array}\right]+\left[\begin{array}{c}
0 \\
\dot{\theta}_{r y} \\
0
\end{array}\right]=\left[\begin{array}{c}
\omega_{b x} \cos \theta_{r y}-\omega_{b z} \sin \theta_{r y} \\
\omega_{b y}+\dot{\theta}_{r y} \\
\omega_{b x} \cos \theta_{r y}+\omega_{b z} \sin \theta_{r y}
\end{array}\right] .
$$

The coordinate transformation matrix from the base plate to the roll gimbal is

$$
C_{b}^{r}=\left[\begin{array}{ccc}
\cos \theta_{r y} & 0 & -\sin \theta_{r y} \\
0 & 1 & 0 \\
\sin \theta_{r y} & 0 & \cos \theta_{r y}
\end{array}\right]
$$

The angular rates of pitch gimbal around three axes could be derived and written as

$$
\begin{aligned}
{\left[\begin{array}{c}
\omega_{p x} \\
\omega_{p y} \\
\omega_{p z}
\end{array}\right]=} & C_{r}^{p} C_{b}^{r}\left[\begin{array}{c}
\omega_{b x} \\
\omega_{b y} \\
\omega_{b z}
\end{array}\right]+C_{r}^{p}\left[\begin{array}{c}
0 \\
\dot{\theta}_{r y} \\
0
\end{array}\right]+\left[\begin{array}{c}
\dot{\theta}_{p x} \\
0 \\
0
\end{array}\right] \\
= & {\left[\begin{array}{c}
\omega_{b x} \cos \theta_{r y}-\omega_{b z} \sin \theta_{r y}+\dot{\theta}_{p x} \\
\left(\omega_{b y}+\dot{\theta}_{r y}\right) \cos \theta_{p x}+\left(\omega_{b x} \sin \theta_{r y}+\omega_{b z} \cos \theta_{r y}\right) \sin \theta_{p x} \\
\left(\omega_{b x} \sin \theta_{r y}+\omega_{b z} \cos \theta_{r y}\right) \cos \theta_{p x}-\left(\omega_{b y}+\dot{\theta}_{r y}\right) \sin \theta_{p x}
\end{array}\right] . }
\end{aligned}
$$

The coordinate transformation matrix from the roll gimbal to the pitch gimbal is

$$
C_{r}^{p}=\left[\begin{array}{ccc}
1 & 0 & 0 \\
0 & \cos \theta_{p x} & \sin \theta_{p x} \\
0 & -\sin \theta_{p x} & \cos \theta_{p x}
\end{array}\right]
$$


The angular rates of yaw gimbal around three axes could be derived and written as

$$
\begin{aligned}
{\left[\begin{array}{c}
\omega_{y x} \\
\omega_{y y} \\
\omega_{y z}
\end{array}\right]=} & C_{p}^{y} C_{r}^{p} C_{b}^{r}\left[\begin{array}{c}
\omega_{b x} \\
\omega_{b y} \\
\omega_{b z}
\end{array}\right]+C_{p}^{y} C_{r}^{p}\left[\begin{array}{c}
0 \\
\dot{\theta}_{r y} \\
0
\end{array}\right]+C_{p}^{y}\left[\begin{array}{c}
\dot{\theta}_{p x} \\
0 \\
0
\end{array}\right]+\left[\begin{array}{c}
0 \\
0 \\
\dot{\theta}_{y z}
\end{array}\right] \\
= & {\left[\begin{array}{c}
\left(\omega_{b x} \cos \theta_{r y}-\omega_{b z} \sin \theta_{r y}+\dot{\theta}_{p x}\right) \cos \theta_{y z}+\left[\left(\omega_{b y}+\dot{\theta}_{r y}\right) \cos \theta_{p x}+\left(\omega_{b x} \sin \theta_{r y}+\omega_{b z} \cos \theta_{r y}\right) \sin \theta_{y z}\right] \sin \theta_{y z} \\
{\left[\left(\omega_{b y}+\dot{\theta}_{r y}\right) \cos \theta_{p x}+\left(\omega_{b x} \sin \theta_{r y}+\omega_{b z} \cos \theta_{r y}\right) \sin \theta_{y z}\right] \cos \theta_{y z}-\left(\omega_{b x} \cos \theta_{r y}-\omega_{b z} \sin \theta_{r y}+\dot{\theta}_{p x}\right) \sin \theta_{y z}} \\
\left(\omega_{b x} \sin \theta_{r y}+\omega_{b z} \cos \theta_{r y}\right) \cos \theta_{p x}-\left(\omega_{b y}+\dot{\theta}_{r y}\right) \sin \theta_{p x}+\dot{\theta}_{y z}
\end{array}\right] . }
\end{aligned}
$$

The coordinate transformation matrix from the pitch gimbal to the yaw gimbal is

$$
C_{p}^{y}=\left[\begin{array}{ccc}
\cos \theta_{y z} & \sin \theta_{y z} & 0 \\
-\sin \theta_{y z} & \cos \theta_{y z} & 0 \\
0 & 0 & 1
\end{array}\right]
$$

Using the equations from (1) to (6), the angular rates of three-axis ISP around three pivot axes can be written as

$$
\begin{aligned}
{\left[\begin{array}{c}
\omega_{p x} \\
\omega_{r y} \\
\omega_{y z}
\end{array}\right] } & =\left[\begin{array}{c}
\omega_{b x} \cos \theta_{r y}-\omega_{b z} \sin \theta_{r y}+\dot{\theta}_{p x} \\
\omega_{b y}+\dot{\theta}_{r y} \\
\left(\omega_{b x} \sin \theta_{r y}+\omega_{b z} \cos \theta_{r y}\right) \cos \theta_{p x}-\left(\omega_{b y}+\dot{\theta}_{r y}\right) \sin \theta_{p x}+\dot{\theta}_{y z}
\end{array}\right] \\
& =\left[\begin{array}{ccc}
\cos \theta_{r y} & 0 & -\sin \theta_{r y} \\
0 & 1 & 0 \\
\cos \theta_{p x} \sin \theta_{r y} & -\sin \theta_{p x} & \cos \theta_{p x} \cos \theta_{r y}
\end{array}\right] \cdot\left[\begin{array}{c}
\omega_{b x} \\
\omega_{b y} \\
\omega_{b z}
\end{array}\right]+\left[\begin{array}{ccc}
1 & 0 & 0 \\
0 & 1 & 0 \\
0 & -\sin \theta_{p x} & 1
\end{array}\right] \cdot\left[\begin{array}{c}
\dot{\theta}_{p x} \\
\dot{\theta}_{r y} \\
\dot{\theta}_{y z}
\end{array}\right] .
\end{aligned}
$$

2.3. Dynamics of Three Gimbals in Three-Axis ISP. Assuming each gimbal of three-axis ISP is a symmetrical rigid structure, according to the Newton-Euler rotational equation, the torques of three gimbals are written as

$$
\mathbf{T}=\mathbf{J} \dot{\omega}+\boldsymbol{\omega} \times \mathbf{J} \boldsymbol{\omega} .
$$

For the roll gimbal, the torque about each axis is $T_{r}=\left[T_{r x} T_{r y} T_{r z}\right]^{T}$, and

$$
\left\{\begin{array}{l}
T_{r x}=J_{r x} \dot{\omega}_{r x}-\left(J_{r y}-J_{r z}\right) \omega_{r y} \omega_{r z} \\
T_{r y}=J_{r y} \dot{\omega}_{r y}-\left(J_{r x}-J_{r z}\right) \omega_{r x} \omega_{r z} \\
T_{r z}=J_{r z} \dot{\omega}_{r z}-\left(J_{r x}-J_{r y}\right) \omega_{r x} \omega_{r y}
\end{array}\right.
$$

where $J_{r x}, J_{r y}$, and $J_{r z}$ are moments of inertia about three axes of the roll gimbal, respectively.

For the pitch gimbal, the torque acting on each axis is $T_{p}=\left[T_{p x} T_{p y} T_{p z}\right]^{T}$, and

$$
\left\{\begin{array}{l}
T_{p x}=J_{p x}\left(\dot{\omega}_{r x}+\ddot{\theta}_{p x}\right)-\left(J_{r y}-J_{r z}\right)\left(\omega_{r z} \sin \theta_{p x}+\omega_{r y} \cos \theta_{p x}\right)\left(\omega_{r z} \cos \theta_{p x}-\omega_{r y} \sin \theta_{p x}\right) \\
T_{p y}=J_{p y}\left(\left(\dot{\omega}_{r y}+\dot{\theta}_{p x} \omega_{r z}\right) \cos \theta_{p x}-\left(\omega_{r z}+\dot{\theta}_{p x} \omega_{r y}\right) \sin \theta_{p x}\right)-\left(J_{r x}-J_{r z}\right)\left(\omega_{r z} \cos \theta_{p x}-\omega_{r y} \sin \theta_{p x}\right)\left(\omega_{r x}+\dot{\theta}_{p x}\right) \\
T_{p z}=J_{p z}\left(-\dot{\omega}_{r y} \sin \theta_{p x}-\dot{\theta}_{p x} \omega_{r y} \cos \theta_{p x}+\omega_{r z} \cos \theta_{p x}-\dot{\theta}_{p x} \omega_{r z} \sin \theta_{p x}\right)
\end{array}\right.
$$

where $J_{p x}, J_{p y}$, and $J_{p z}$ are moments of inertia about three axes of the pitch gimbal, respectively.
For the yaw gimbal, the torque acting on each axis is $T_{y}=\left[T_{y x} T_{y y} T_{y z}\right]^{T}$, and 


$$
\left\{\begin{array}{c}
T_{y x}=J_{y x}\left[\begin{array}{c}
\left(\dot{\omega}_{r x}+\ddot{\theta}_{p x}\right) \cos \theta_{y z}-\dot{\theta}_{y z}\left(\omega_{r x}+\dot{\theta}_{p x}\right) \sin \theta_{y z}+\dot{\theta}_{y z}\left(\omega_{r y} \cos \theta_{p x}+\omega_{r z} \sin \theta_{p x}\right) \cos \theta_{y z} \\
+\left(\dot{\omega}_{r y} \cos \theta_{p x}-\dot{\theta}_{p x} \omega_{r y} \sin \theta_{p x}+\dot{\omega}_{r z} \sin \theta_{p x}+\dot{\theta}_{p x} \omega_{r z} \cos \theta_{p x}\right) \sin \theta_{y z}
\end{array}\right] \\
-\left(J_{y y}-J_{y z}\right)\left(\omega_{r z} \cos \theta_{p x}-\omega_{r y} \sin \theta_{p x}+\dot{\theta}_{y z}\right)\left[\left(\omega_{r z} \sin \theta_{p x}+\omega_{r y} \cos \theta_{p x}\right) \cos \theta_{y z}-\left(\omega_{r x}+\dot{\theta}_{y z}\right) \sin \theta_{y z}\right] \\
T_{y y}=J_{y y}\left[\begin{array}{c}
-\left(\dot{\omega}_{r x}+\ddot{\theta}_{p x}\right) \sin \theta_{y z}-\dot{\theta}_{y z}\left(\omega_{r x}+\dot{\theta}_{p x}\right) \cos \theta_{y z}-\dot{\theta}_{y z}\left(\omega_{r y} \cos \theta_{p x}+\omega_{r z} \sin \theta_{p x}\right) \sin \theta_{y z} \\
+\left(\dot{\omega}_{r y} \cos \theta_{p x}-\dot{\theta}_{p x} \omega_{r y} \sin \theta_{p x}+\dot{\omega}_{r z} \sin \theta_{p x}+\dot{\theta}_{p x} \omega_{r z} \cos \theta_{p x}\right) \cos \theta_{y z}
\end{array}\right] \\
-\left(J_{y z}-J_{y x}\right)\left(\omega_{r z} \cos \theta_{p x}-\omega_{r y} \sin \theta_{p x}+\dot{\theta}_{y z}\right)\left[\left(\omega_{r z} \sin \theta_{p x}+\omega_{r y} \cos \theta_{p x}\right) \sin \theta_{y z}+\left(\omega_{r x}+\dot{\theta}_{y z}\right) \cos \theta_{y z}\right] \\
T_{y z}=J_{y z}\left(-\omega_{r y} \sin \theta_{p x}-\dot{\theta}_{p x} \omega_{r y} \cos \theta_{p x}+\dot{\omega}_{r z} \cos \theta_{p x}-\dot{\theta}_{p x} \omega_{r z} \sin \theta_{p x}+\ddot{\theta}_{y z}\right)
\end{array}\right.
$$

where $J_{y x}, J_{y y}$, and $J_{y z}$ are moments of inertia about three axes of the yaw gimbal, respectively.

Therefore, the torques acting on three pivot axes of the three-axis ISP could be expressed as

$$
\left\{\begin{array}{l}
T_{x}=T_{p x}+\left(C_{p}^{y}\right)^{-1} T_{y z} \\
T_{y}=T_{r y}+\left(C_{p}^{y} C_{r}^{p}\right)^{-1} T_{y z}+\left(C_{r}^{p}\right)^{-1} T_{p x} \\
T_{z}=T_{y z}
\end{array}\right.
$$

The torques about three pivot axes of three-axis ISP $T_{x}$, $T_{y}$, and $T_{z}$ are the synthesized torques about $X_{p}$ axis of the pitch gimbal, $Y_{r}$ axis of the roll gimbal, and $Z_{y}$ axis of the yaw gimbal, respectively. $T_{x}$ is the summation of $T_{p x}$ (torque acting on the pivot axis of the pitch gimbal) and $\left(C_{p}^{y}\right)^{-1} T_{y z}$ is the component of $T_{y z}$ about $X_{p}$ axis. Similarly, $T_{y}$ is the summation of $T_{r y}$ (torque acting on pivot axis of the roll gimbal), $\left(C_{p}^{y} C_{r}^{p}\right)^{-1} T_{y z}$ is the component of $T_{y z}$ about $Y_{r}$ axis, and $\left(C_{r}^{p}\right)^{-1} T_{p x}$ is the component of $T_{p x}$ about $Y_{r}$ axis.

Furthermore, substituting torques of three gimbals in (9)-(11) into (12) and using the coordinate transformation matrices in (2), (4), and (6), we can write

$$
\left\{\begin{array}{l}
T_{x}=\left(J_{y x}+J_{p x}\right) \ddot{\theta}_{p x}+J_{y z} \dot{\theta}_{y z} \dot{\theta}_{r y}-\left(J_{y z}-J_{y y}+J_{r z}-J_{r y}\right) \dot{\theta}_{r y}^{2} \theta_{p x} \\
+\left(J_{y z}-J_{y y}+J_{r z}-J_{r y}-J_{y x}-J_{p x}\right) \dot{\theta}_{r y} \omega_{b z}+J_{y z} \dot{\theta}_{y z} \omega_{b y} \\
+\left(J_{y x}+J_{p x}\right) \dot{\omega}_{b x}+\left(J_{y z}-J_{y y}+J_{r z}-J_{r y}\right) \omega_{b y} \omega_{b z}, \\
T_{y}=\left(J_{y x}+J_{p y}+J_{r y}\right) \ddot{\theta}_{r y}-J_{y z} \theta_{p x} \ddot{\theta}_{y z}+\left(J_{y z}+J_{p z}-J_{y x}-J_{p y}\right) \dot{\theta}_{p x} \dot{\theta}_{r y} \theta_{p x}-J_{y x} \dot{\theta}_{p x} \dot{\theta}_{y z} \\
+\left(J_{y x}+J_{p y}-J_{y z}-J_{p z}\right) \dot{\theta}_{p x} \dot{\theta}_{r y} \omega_{b x}+\left(J_{y x}+J_{p y}-J_{y z}+J_{p x}\right) \dot{\theta}_{p x} \omega_{b z} \\
-J_{y x} \dot{\theta}_{y z} \omega_{b x}+\left(J_{y x}+J_{p y}+J_{r y}\right) \dot{\omega}_{b y}-\left(J_{p z}+J_{r z}-J_{p x}-J_{r x}\right) \omega_{b x} \omega_{b z}, \\
T_{z}=J_{y z} \ddot{\theta}_{y z}-J_{y z} \theta_{p x} \ddot{\theta}_{r y}-J_{y z} \dot{\theta}_{p x} \dot{\theta}_{r y}-J_{y z} \dot{\theta}_{p x} \omega_{b y}+J_{y z} \dot{\theta}_{r y} \omega_{b x}+J_{y z} \dot{\omega}_{b z} .
\end{array}\right.
$$

There are cross-coupling terms including angular rates of the base plate and two gimbals in (13). The coupling torque between the base plate and the gimbal is defined as the base coupling torque, and the coupling torque among three gimbals is defined as the gimbal coupling torque.

For the pitch gimbal, the gimbal coupling torque between the pitch gimbal and other gimbals is

$$
T_{p}^{(r / y)}=J_{y z} \dot{\theta}_{y z} \dot{\theta}_{r y}-\left(J_{y z}-J_{y y}+J_{r z}-J_{r y}\right) \dot{\theta}_{r y}^{2} \theta_{p x} .
$$

The base coupling torque between the pitch gimbal and the base plate is

$$
\begin{aligned}
T_{p}^{b}= & \left(J_{y z}-J_{y y}+J_{r z}-J_{r y}-J_{y x}-J_{p x}\right) \dot{\theta}_{r y} \omega_{b z} \\
& +J_{y z} \dot{\theta}_{y z} \omega_{b y}+\left(J_{y x}+J_{p x}\right) \dot{\omega}_{b x} \\
& +\left(J_{y z}-J_{y y}+J_{r z}-J_{r y}\right) \omega_{b y} \omega_{b z} .
\end{aligned}
$$

For the roll gimbal, the gimbal coupling torque between the roll gimbal and other gimbals is

$$
\begin{aligned}
T_{r}^{(p / y)}= & -J_{y z} \theta_{p x} \ddot{\theta}_{y z}-J_{y x} \dot{\theta}_{p x} \dot{\theta}_{y z} \\
& +\left(J_{y z}+J_{p z}-J_{y x}-J_{p y}\right) \dot{\theta}_{p x} \dot{\theta}_{r y} \theta_{p x} .
\end{aligned}
$$

The base coupling torque between the roll gimbal and the base plate is

$$
\begin{aligned}
T_{r}^{b}= & \left(J_{y x}+J_{p y}-J_{y z}-J_{p z}\right) \dot{\theta}_{p x} \dot{\theta}_{r y} \omega_{b x} \\
& +\left(J_{y x}+J_{p y}-J_{y z}+J_{p x}\right) \dot{\theta}_{p x} \omega_{b z} \\
& -J_{y x} \dot{\theta}_{y z} \omega_{b x}+\left(J_{y x}+J_{p y}+J_{r y}\right) \dot{\omega}_{b y} \\
& -\left(J_{p z}+J_{r z}-J_{p x}-J_{r x}\right) \omega_{b x} \omega_{b z} .
\end{aligned}
$$

For the yaw gimbal, the gimbal coupling torque between the yaw gimbal and other gimbals is 


$$
T_{y}^{(p / r)}=-J_{y z} \theta_{p x} \ddot{\theta}_{r y}-J_{y z} \dot{\theta}_{p x} \dot{\theta}_{r y} .
$$

The base coupling torque between the yaw gimbal and the base plate is

$$
T_{y}^{b}=-J_{y z} \dot{\theta}_{p x} \omega_{b y}+J_{y z} \dot{\theta}_{r y} \omega_{b x}+J_{y z} \dot{\omega}_{b z} .
$$

Using equations (14)-(19), equation (13) could be rewritten into

$$
\left\{\begin{array}{l}
T_{x}=\left(J_{y x}+J_{p x}\right) \ddot{\theta}_{p x}+T_{p}^{(r / y)}+T_{p}^{b}, \\
T_{y}=\left(J_{y x}+J_{p y}+J_{r y}\right) \ddot{\theta}_{r y}+T_{r}^{(p / y)}+T_{r}^{b}, \\
T_{z}=J_{y z} \ddot{\theta}_{y z}+T_{y}^{(p / r)}+T_{y}^{b} .
\end{array}\right.
$$

Therefore, the gimbal couplings among three gimbals affect the attitude stabilization precisions of three gimbals, and the gimbal coupling torque increases with the number of coupling gimbals. Moreover, the base coupling torque also affects the attitude stabilization precisions of three gimbals.

For the static base plate when the swaying platform and other carriers do not generate disturbances and conduct rapid attitude maneuver, there are

$$
\left\{\begin{array}{l}
\omega_{b x}=\omega_{b y}=\omega_{b z}=0, \\
T_{p}^{b}=T_{r}^{b}=T_{y}^{b}=0 .
\end{array}\right.
$$

Substituting (21) into (20), we can write

$$
\left\{\begin{array}{l}
T_{x}=\left(J_{y x}+J_{p x}\right) \ddot{\theta}_{p x}+T_{p}^{(r / y)}, \\
T_{y}=\left(J_{y x}+J_{p y}+J_{r y}\right) \ddot{\theta}_{r y}+T_{r}^{(p / y)}, \\
T_{z}=J_{y z} \ddot{\theta}_{y z}+T_{y}^{(p / r)} .
\end{array}\right.
$$

Therefore, the base coupling torque could be neglected when the base plate works at static status because it does not affect the attitude stabilization precisions of three gimbals. Only when the base plate works at dynamic status, the base coupling torque would affect the attitude stabilization precisions of three gimbals.

2.4. Single Gimbal Torque Motor of Three-Axis ISP. The driving torques generated by the torque motor control the rotation of gimbal. The control diagram of a gimbal motor is presented in Figure $3 \theta$ is the rotational angle of gimbal motor. $u$ is the control voltage of gimbal motor. $L$ is the armature inductance. $R$ is the armature resistance. $k_{t}$ is the torque coefficient. $N$ is gear ratio. $T_{m}$ is the driving torque, and $k_{e}$ is the back-EMF coefficient. The driving moment of gimbal motor is

$$
T_{m}=\frac{k_{t}}{L s+R}\left(u-k_{e} \dot{\theta}\right) .
$$

The electromechanical models of three gimbal motors in three-axis ISP could be written as

$$
\left\{\begin{array}{l}
T_{x}=\frac{k_{t p}}{L_{p} s+R_{p}}\left(u_{p}-k_{e p} \dot{\theta}_{p x}\right)=\left(J_{y x}+J_{p x}\right) \ddot{\theta}_{p x}+T_{p}^{(r / y)}+T_{p}^{b}, \\
T_{y}=\frac{k_{t r}}{L_{r} s+R_{r}}\left(u_{r}-k_{e r} \dot{\theta}_{r y}\right)=\left(J_{y x}+J_{p y}+J_{r y}\right) \ddot{\theta}_{r y}+T_{r}^{(p / y)}+T_{r}^{b}, \\
T_{z}=\frac{k_{t y}}{L_{y} s+R_{y}}\left(u_{y}-k_{e y} \dot{\theta}_{y z}\right)=J_{y z} \ddot{\theta}_{y z}+T_{y}^{(p / r)}+T_{y}^{b} .
\end{array}\right.
$$

If coupling torques including the base coupling torque and the gimbal coupling torque are effectively compensated, (24) could be simplified as

$$
\left\{\begin{array}{l}
\frac{k_{t p}}{L_{p} s+R_{p}}\left(u_{p}-k_{e p} \dot{\theta}_{p x}\right)=\left(J_{y x}+J_{p x}\right) \ddot{\theta}_{p x}, \\
\frac{k_{t r}}{L_{r} s+R_{r}}\left(u_{r}-k_{e r} \dot{\theta}_{r y}\right)=\left(J_{y x}+J_{p y}+J_{r y}\right) \ddot{\theta}_{r y}, \\
\frac{k_{t y}}{L_{y} s+R_{y}}\left(u_{y}-k_{e y} \dot{\theta}_{y z}\right)=J_{y z} \ddot{\theta}_{y z} .
\end{array}\right.
$$

Therefore, the rotational controls around pivot axes of the three-axis ISP could be dominated by the torque motors mounted on three gimbals.

\subsection{AMB System of Three-Axis ISP}

2.5.1. Axial AMB System. The axial AMB system consists of eight $A M B s$ at low end and four AMBs at high end of yaw gimbal as shown in Figure 4. The four pairs of axial AMBs (A1-B1, A2-B2, A3-B3, and A4-B4) at lower and upper end in Figure 4 control the translation of yaw gimbal in axial direction, and then the yaw gimbal is stably suspended at the axial equilibrium position. Based on [16], the suspension force in axial direction could be written as

$$
f_{z}=k_{i z} i_{z}-k_{d z} d_{z}
$$

where $k_{i z}$ is the axial current stiffness and $k_{d z}$ is the axial displacement stiffness.

The relationships amongst the axial suspension force, the axial displacement, and the axial control current are plotted in Figures 5(a) and 5(b), respectively. These two figures show 


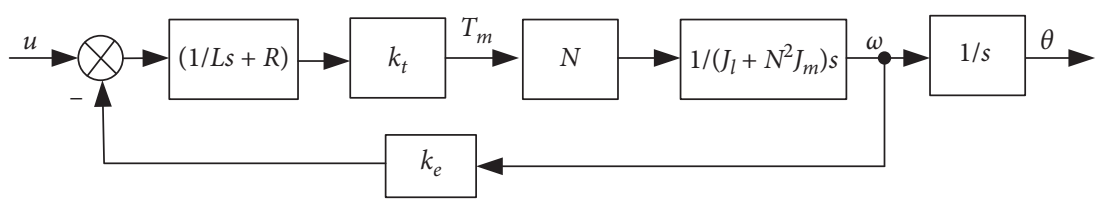

Figure 3: Control diagram of torque motor on gimbal.

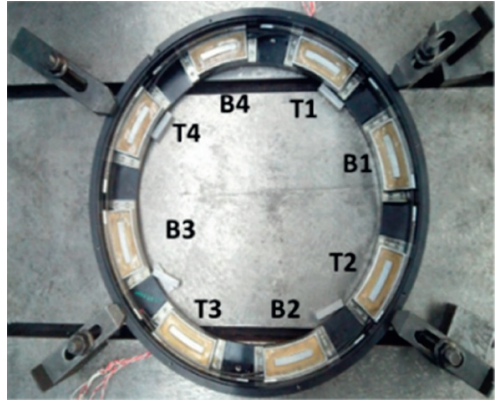

(a)
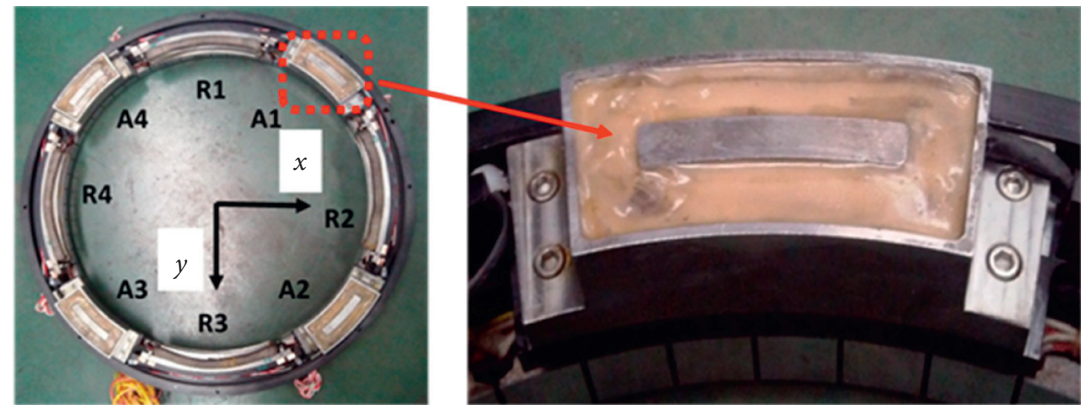

(b)

Figure 4: The axial AMB system. (a) Axial AMB at lower end. (b) Axial AMB at upper end and the single AMB.

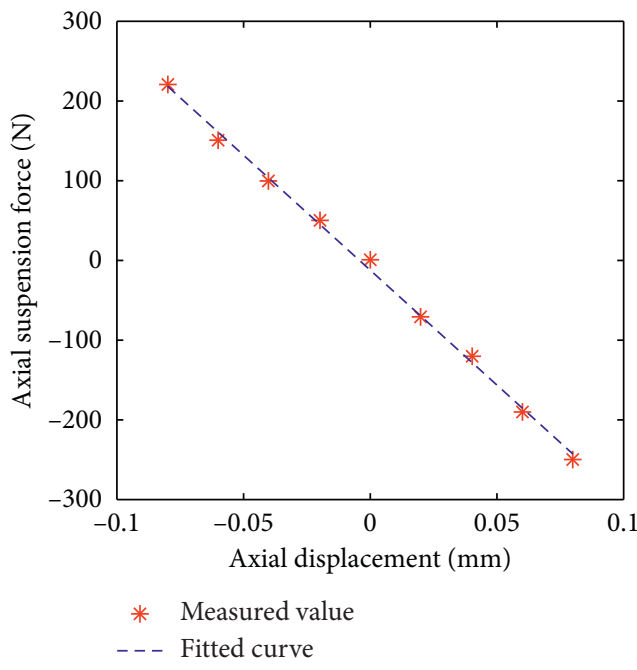

(a)

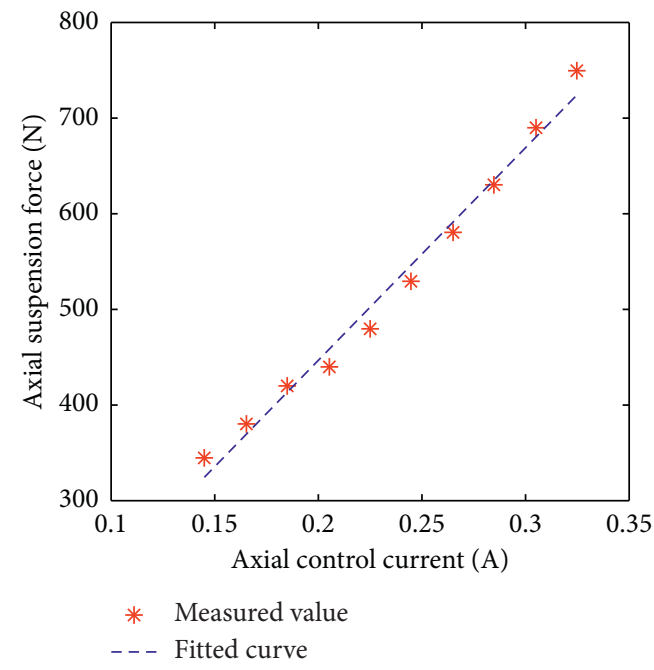

(b)

FIgURE 5: (a) Axial suspension force versus control displacement. (b) Axial suspension force versus control current.

that the axial suspension force is proportional to both control current and control displacement. The axial current stiffness $k_{i z}$ is found to be $2000 \mathrm{~N} / \mathrm{A}$, and the axial displacement stiffness $k_{d z}$ is found to be $-3000 \mathrm{~N} / \mathrm{mm}$.

2.5.2. Radial AMB System. The radial AMB system has two pairs of radial AMBs as shown in Figure 6. One pair of radial AMBs (R2-R4) control the translation of yaw gimbal along $X$ axis, and another pair of radial AMBs (R1-R3) control the translation of yaw gimbal along $Y$ axis. Since the radial AMB system is symmetrical, the current stiffness in $X$ axis equals that in $Y$ axis, and the displacement stiffness in $X$ axis equals that in $Y$ axis. The suspension forces along $X$ and $Y$ axes are linearized and written as

$$
\left\{\begin{array}{l}
f_{x}=k_{i x} i_{x}-k_{d x} d_{x}, \\
f_{y}=k_{i y} i_{y}-k_{d y} d_{y},
\end{array}\right.
$$

where $k_{i x}=k_{i y}$ is the radial current stiffness and $k_{d x}=k_{d y}$ is the radial displacement stiffness.

The radial suspension force is proportional to both control current and radial displacement in Figures 7(a) and 7(b). The radial current stiffness $k_{i x}$ is $300 \mathrm{~N} / \mathrm{A}$, and the radial displacement stiffness $k_{d x}$ is $-480 \mathrm{~N} / \mathrm{mm}$.

2.5.3. Control of the AMB System in Three-Axis ISP. The force analysis of the yaw gimbal with an $A M B$ system is illustrated in Figure 8, the windings of radial and axial AMBs 


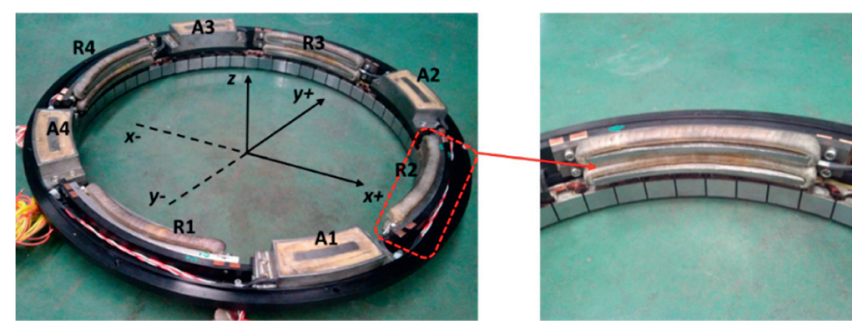

Figure 6: Radial AMB system and its single AMB.

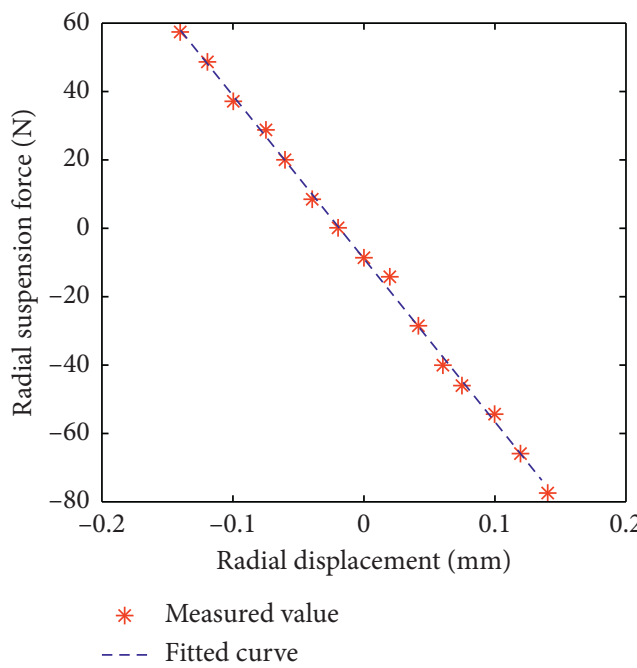

(a)

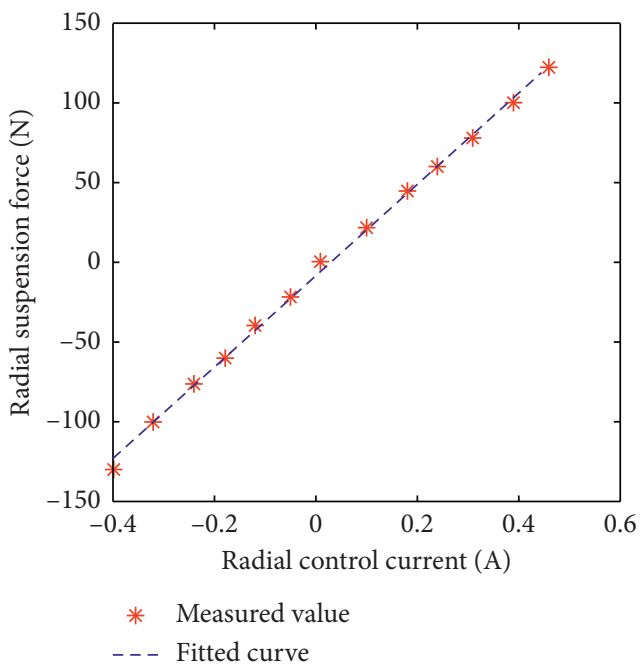

(b)

FIgURE 7: (a) Radial suspension force versus radial displacement. (b) Radial suspension force versus control current.

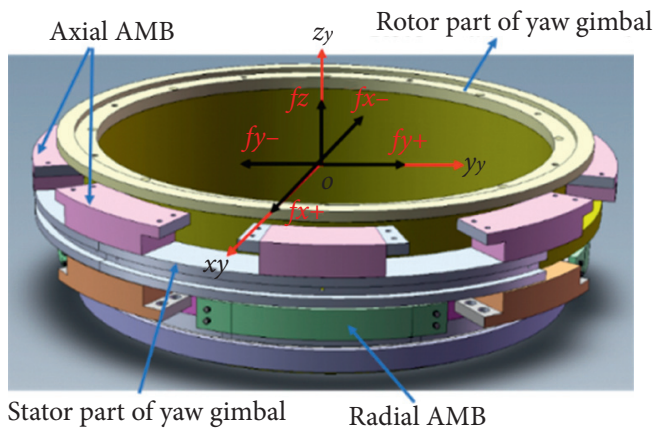

Figure 8: Force analysis of the yaw gimbal with an AMB system.

are mounted on the stator part of yaw gimbal, and then the rotor part of yaw gimbal is suspended by the suspension forces of AMB system. Therefore, the equations of yaw gimbal's motion in radial and axial directions could be expressed into

$$
\left\{\begin{array}{l}
m \ddot{d}_{x}=f_{x+}-f_{x-}, \\
m \ddot{d}_{y}=f_{y+}-f_{y-}, \\
m \ddot{d}_{z}=f_{z} .
\end{array}\right.
$$

Considering that the rotational speed of yaw gimbal around the axial pivot axis is slow compared with the highspeed rotational machine such as flywheel energy storage system [36], the gyroscopic effect of the yaw gimbal is not considered. The translational control models of yaw gimbal in radial and axial directions are decoupled, and the translational control of yaw gimbal along three axes is similar, so the control loop of radial translation is chosen as an example in Figure 9. The PD control model is applied with the proportional coefficient $k_{P X}$, the derivative coefficient $k_{D x} . k_{s}$ is the sensitivity of eddy current displacement 


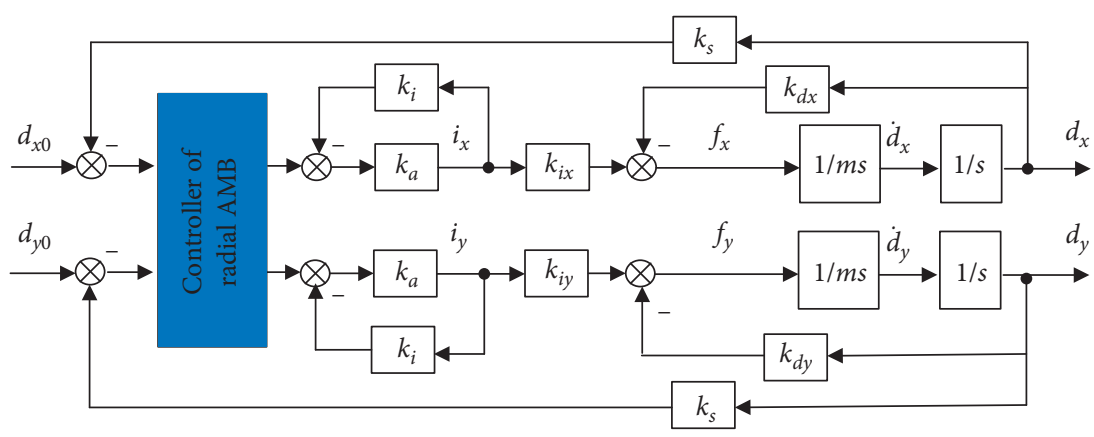

Figure 9: Control diagram of the magnetic suspension system in radial directions.

sensor, and $k_{a}$ is the amplification coefficient. The transfer function of translation motion could be expressed as

$$
G(s)=\frac{k_{i x} k_{a} k_{P x}+k_{i x} k_{a} k_{D x} s}{m s^{2}+k_{i x} k_{a} k_{s} k_{D x} s+k_{i x} k_{a} k_{s} k_{P x}-k_{d x}} .
$$

The translational control loop of the yaw gimbal will be stable if the control model satisfies the following conditions:

$$
\left\{\begin{array}{l}
k_{D x} \geq 0 \\
k_{i x} k_{a} k_{s} k_{P x}-k_{d x} \geq 0
\end{array}\right.
$$

Therefore, for the single closed loop of the AMB system, the proportional coefficient could determine the stability of the yaw gimbal with an AMB system, and the derivative coefficient also affect the stability of the yaw gimbal with an AMB system.

\section{Experiment Verification}

3.1. Control Diagram of Three-Axis ISP with the AMB System. As illustrated in Figure 10, the whole control diagram of three-axis ISP consists of four parts including the control module of torque motors, the compensation module of base coupling, the compensation module of gimbal coupling, and the cross-feedback module. For the control module of torque motors, the control voltage of torque motor is the control input to drive three gimbals, and the attitude control of the three-axis ISP could be realized. The angular displacement of each gimbal is the feedback signal to realize closed-loop control about attitude of three-axis ISP, and then the attitude stabilization precision of three gimbals would be kept at balanced state. Moreover, the function of compensation module of base coupling in the red dotted-line diagram of Figure 10 is to compensate the base coupling torques $T_{p}^{b}$ in (15), $T_{r}^{b}$ in (17), and $T_{y}^{b}$ in (19). The angular rates of three gimbals and the base plate are used as the feedback signal to compute the compensation terms for minimizing the base coupling torques. In addition, according to the compensation module of gimbal coupling in the blue dotted-line diagram of Figure 10, the angular rates and angular displacements of three gimbals are used as feedback signals to calculate the compensation amounts for the coupling torques $\left(T_{p}^{(r / y)}\right.$ in (14), $T_{y}^{(p / r)}$ in (16), and $T_{r}^{(p / y)}$ in (18)) among three gimbals. So, the coupling torques among three gimbals could be mitigated. Finally, based on those calculated compensation terms for the base coupling torques and the gimbal coupling torques, the cross-feedback module will distribute the compensation terms into different control channels of three-axis ISP. Therefore, the attitude stabilization precisions of three gimbals will be improved by using the cross-feedback module for compensating base coupling torques and gimbal coupling torques.

3.2. Experimental Setup. The whole experimental setup is shown in Figure 11. The self-designed main control unit (MCU) board of three gimbal motors and the AMB system is embedded in three-axis ISP. It consists of a digital signal processor (DSP) TMS320F28335 with 12-bit A/D converter and a digital PWM amplifier at $20 \mathrm{kHz}$, and the sampling frequency is chosen as $20 \mathrm{kHz}$. The control frequency of whole system is $2 \mathrm{kHz}$, and data output frequency sets at $100 \mathrm{~Hz}$. The eddy current displacement sensors are used to measure the dynamic displacements of yaw gimbal in axial and radial directions. Moreover, the position and orientation system (POS) on the payload measures the attitude information of three gimbals, and the payload is mounted on the yaw gimbal. In addition, the three-axis ISP is fixed on a swaying platform which can output relative disturbances on the base plate. Other parameters of three-axis ISP with an AMB system are listed in Table 1.

As illustrated in Figure 12, to experimentally analyze the gimbal coupling and the base coupling, the whole experiment includes three steps as follows.

In the first step, the suspension experiment is conducted to test the suspension stabilization and the active controllability of yaw gimbal with an AMB system. With torque motors of three gimbals switched off and the AMB system switched on, the suspension forces of the AMB system are checked if it could make yaw gimbal stably suspend at the axial and radial equilibrium positions. The purpose of this step is to validate the active controllability of yaw gimbal with the AMB system, and to check if the yaw gimbal suspended by the AMB system has better attitude stabilization precision than the pitch gimbal and the roll gimbal which are supported by mechanical bearings.

Furthermore, the base coupling effect is assessed with different working statuses of three gimbals. In the first case, pitch gimbal and yaw gimbal are locked, and roll gimbal is unlocked. The torque motor of roll gimbal generates control torque to keep roll gimbal stable. The angular displacements of unlocked roll gimbal and locked pitch gimbal are 


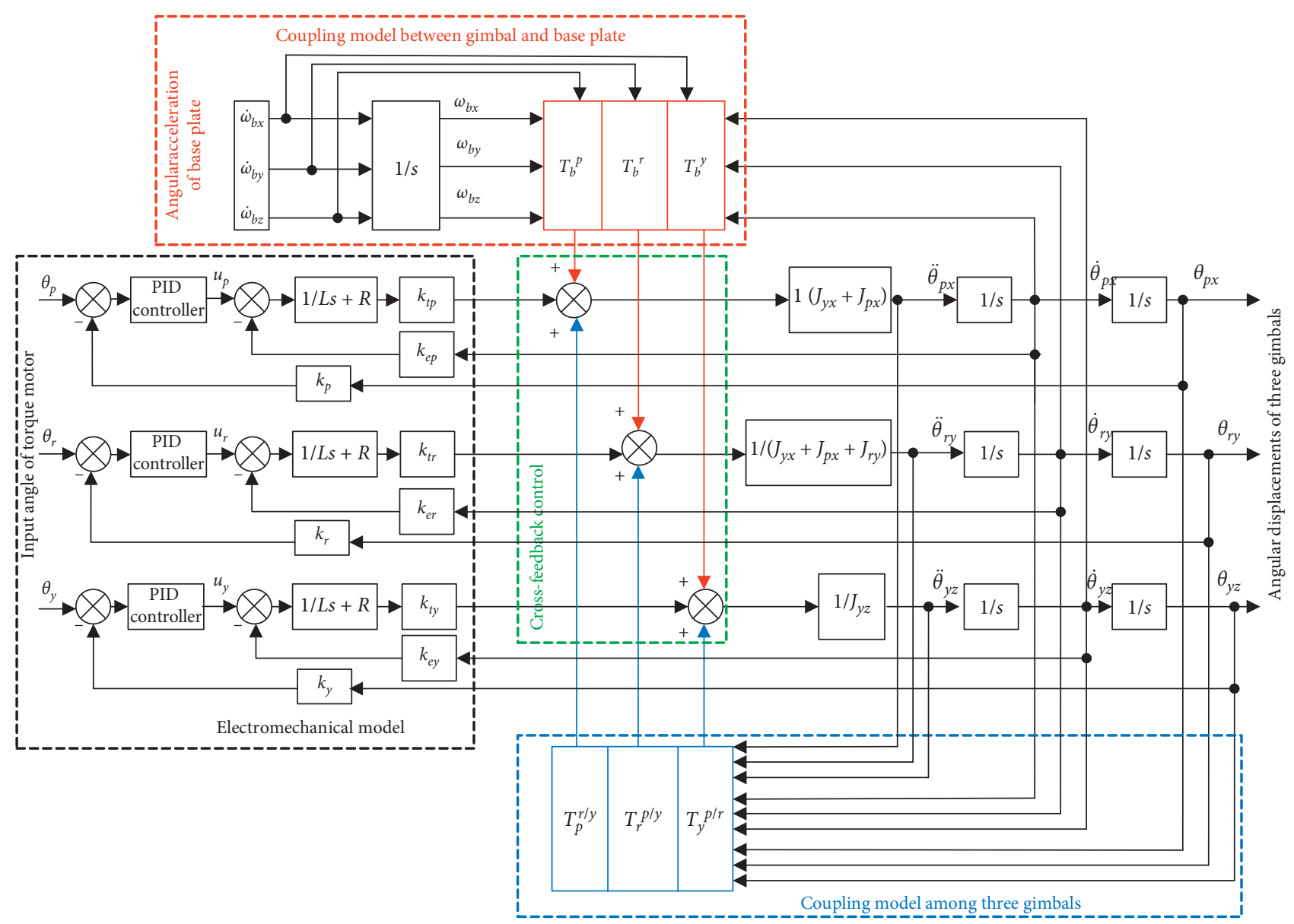

FIGURE 10: Control diagram of three-axis ISP.

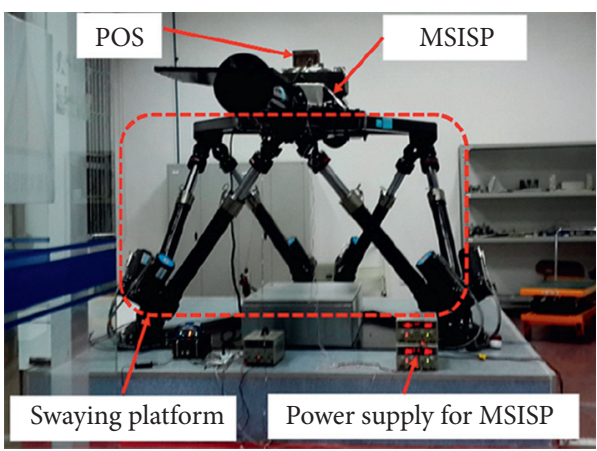

(a)

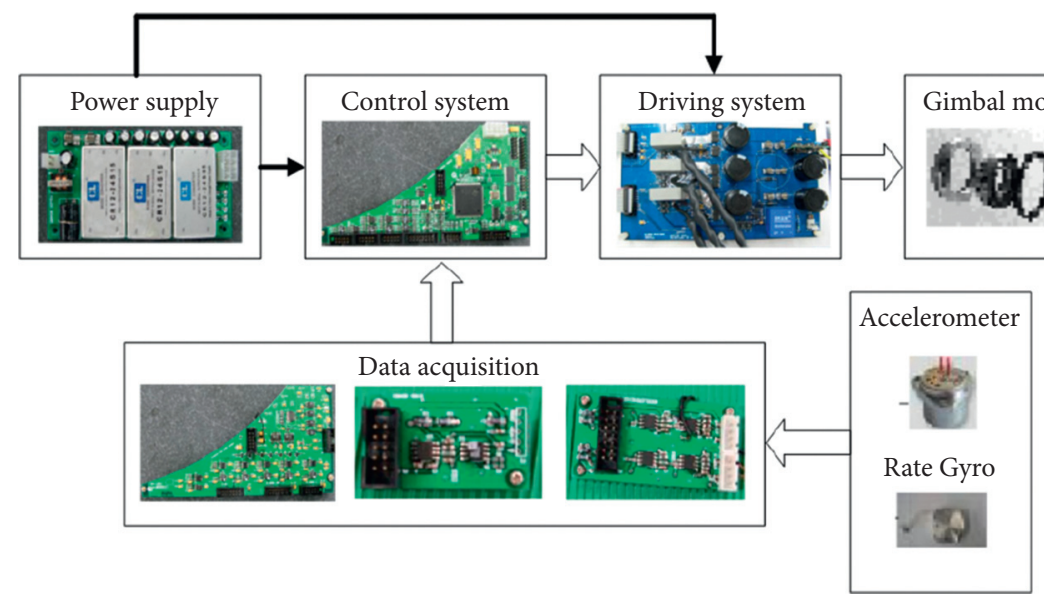

(b)

FIgURE 11: Experimental setup. (a) Experimental system. (b) Control scheme of three-axis ISP.

measured and compared. In the second case, only pitch gimbal is locked, and unlocked roll gimbal and yaw gimbal are controlled by torque motors. The angular displacements of three gimbals are measured and compared. In the third case, three gimbals are unlocked and driven by torque motors, and then the angular displacements of three gimbals are measured and compared. Based on the comparison of angular displacements of three gimbals at different operating statuses, it is found that the gimbal coupling effect increases with the number of unlocked gimbals.

Finally, the cross-feedback control is used to compensate the base coupling when the base plate works at static mode 
TABLE 1: Parameters of three-axis ISP with the AMB system.

\begin{tabular}{lcc}
\hline Symbol & Quantify & Value \\
\hline$k_{i z}$ & Axial current stiffness & $2 \cdot 10^{3} \mathrm{~N} / \mathrm{A}$ \\
$k_{d z}$ & Axial displacement stiffness & $-3 \cdot 10^{6} \mathrm{~N} / \mathrm{m}-$ \\
$k_{d z}$ & Radial current stiffness & $0.3 \cdot 10^{3} \mathrm{~N} / \mathrm{A}$ \\
$k_{d x}$ & Radial displacement stiffness & $-4.8 \cdot 10^{5} \mathrm{~N} / \mathrm{m}^{2}$ \\
$J_{m}$ & Moment of inertia & $3 \cdot 10^{-4} \mathrm{kgm}{ }^{2}$ \\
$k_{a}$ & Amplification coefficient & $0.2 \mathrm{~A} / \mathrm{V}$ \\
$k_{P x}$ & Proportion coefficient of radial AMB & 28 \\
$k_{P z}$ & Proportion coefficient of axial AMB \\
$k_{e}$ & Back-EMF coefficient & 26.7 \\
$k_{t}$ & Torque constant & $0.4 \mathrm{~V} /(\mathrm{rad} / \mathrm{s})$ \\
$m$ & Mass of yaw gimbal & $0.42 \mathrm{Nm} / \mathrm{A}$ \\
$R$ & Armature resistance & $23 \mathrm{~kg}$ \\
$N$ & Gear ratio & $2.6 \Omega$ \\
$k_{s}$ & Displacement sensitivity & 6.7 \\
$k_{D x}$ & Derivative coefficient of radial AMB & $0.3 \mathrm{~V} / \mathrm{mm}$ \\
$k_{D z}$ & Derivative coefficient of axial AMB & 0.7 \\
\hline
\end{tabular}

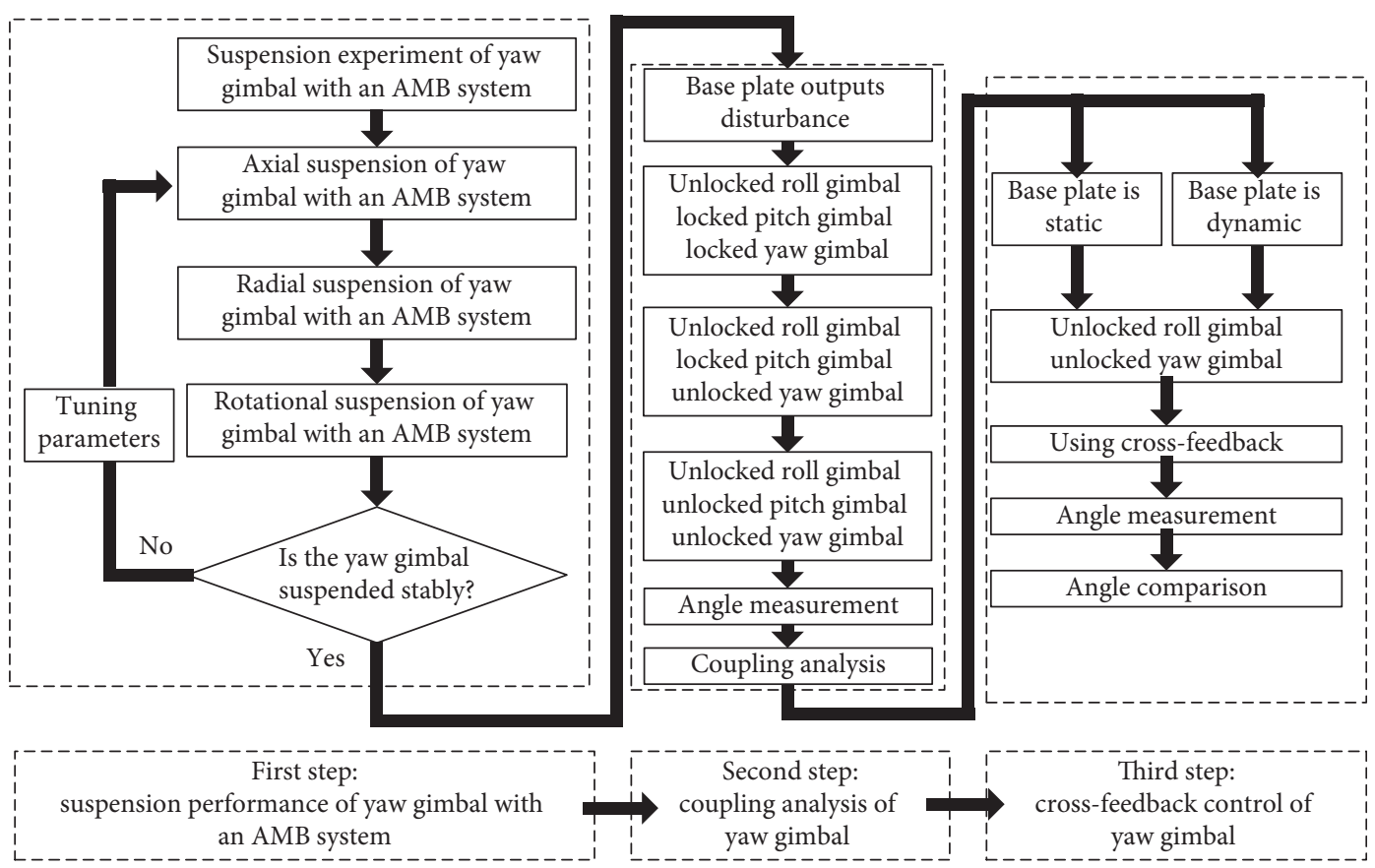

FigURE 12: Experimental steps.

and dynamic mode, respectively. In the first case, the base plate mounted on the swaying platform is kept static. Three gimbals are driven by torque motors to keep them at steady state, and then the angular displacements of three gimbals are measured. In the second case, the swaying platform works at dynamic status. Three gimbals are driven by torque motors to stabilize three gimbals, and the angular displacements of three gimbals are measured. By comparing the angular displacements of three gimbals in the two cases, the experimental test proves the high effectiveness of crossfeedback control for the base coupling effect.

3.3. Suspension Performance of Yaw Gimbal with an $A M B$ System. This suspension experiment is conducted to verify the active controllability of yaw gimbal with an AMB system. The radial displacements of yaw gimbal are plotted in Figure 13(a) when the AMB system is switched on, and then the radial displacements of yaw gimbal equal zero. The control currents of the radial AMB are plotted in Figure $13(\mathrm{~d})$, and they reach a stable amplitude $0.02 \mathrm{~A}$ when the yaw gimbal is stably suspended at the radial equilibrium point. They show that the radial AMB system can stably suspend the yaw gimbal at the radial equilibrium point. Figure 13(b) shows the axial displacements measured by the axial displacement sensors (sensor $Z_{1} Z_{2}, Z_{3}$, and $Z_{4}$ ), and the control currents of axial AMBs are shown in Figure 13(e) when the yaw gimbal is stably suspended at the axial equilibrium point. It indicates that the axial AMB system can keep the yaw gimbal stably suspend at the axial equilibrium 


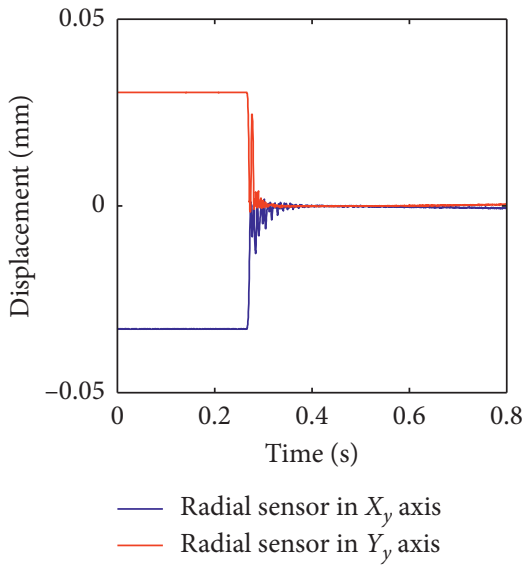

(a)

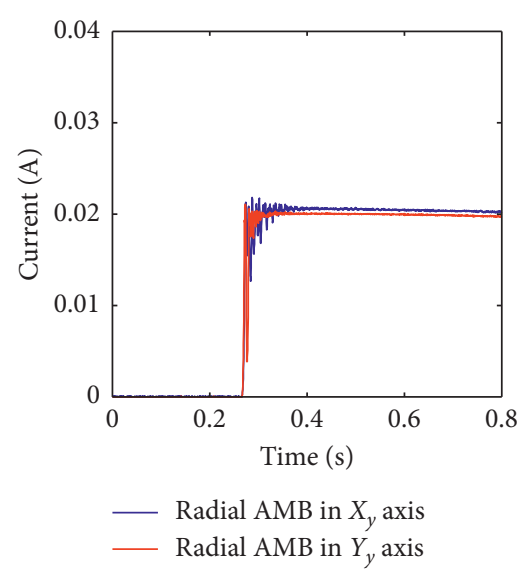

(d)

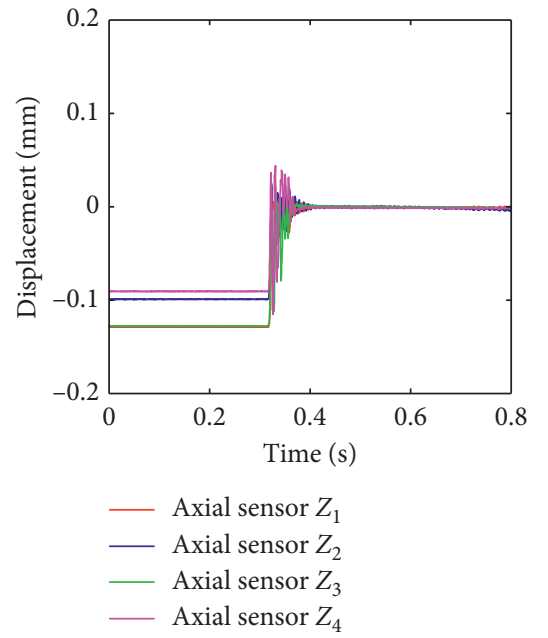

(b)

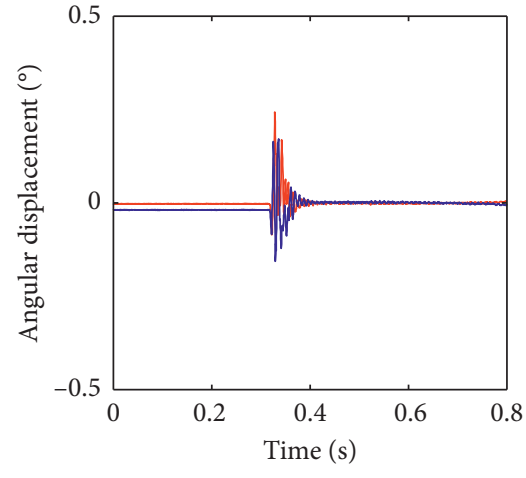

- Angle around $X_{y}$ axis

(c)

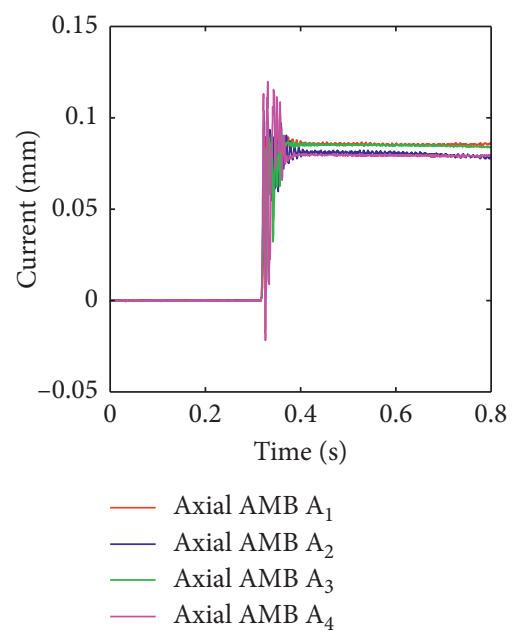

(e)

FIgURE 13: Suspension traces and control currents of yaw gimbal with AMB system. (a) Radial suspension traces. (b) Axial suspension traces. (c) Angular displacement around radial axes. (d) Control currents of radial AMB. (e) Control currents of axial AMB.

point as well. Moreover, the angular displacements of yaw gimbal around $X_{y}$ and $Y_{y}$ axes are depicted in Figure 13(c), the angular displacements are kept at the initial balanced status when the AMB system is turned off, and the angular displacements will be forced back to final balanced status by the suspension forces of AMB system. The root mean square (RMS) of angular displacement around $X_{y}$ axis is $0.0192^{\circ}$, and that around $Y_{y}$ axis is $0.0198^{\circ}$. Therefore, this suspension experiment proves that the suspension forces of $A M B$ system can keep the yaw gimbal stably suspend at the equilibrium positions, and it has the potential to isolate the vibration from other connected gimbals.

3.4. Gimbal Coupling among Three Gimbals in Three-Axis ISP. This experimental test is conducted to analyze the gimbal coupling among three gimbals. The three-axis ISP is mounted on a swaying platform which outputs a disturbance expressed as $r=\sin (0.4 \pi t)$. The first test is to gauge the gimbal coupling of one unlocked gimbal, and then the gimbal coupling of two unlocked gimbals is measured. In the second test, the gimbal coupling of three unlocked gimbals is evaluated. For the locked gimbal, the angular displacement is not affected by the dynamic base plate. For unlocked gimbal, it is driven by torque motor to keep it at the balanced status. The RMS of angular displacement represents the attitude stabilization precision. A large RMS value refers to a low attitude stabilization precision and vice versa.

3.4.1. Gimbal Coupling of Single Unlocked Gimbal. The roll gimbal is driven by the torque motor to keep it at balanced status. The pitch gimbal and the yaw gimbal are locked with the AMB system switched off. When the harmonic vibration is imposed on the base plate, the angular displacements of three gimbals are measured and plotted in Figure 14. The angular displacement of unlocked roll gimbal is shown by the red line in Figure 14(b), and the RMS is found to be 


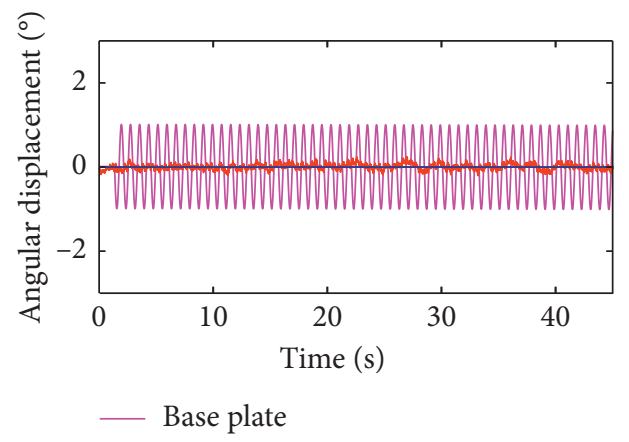

(a)

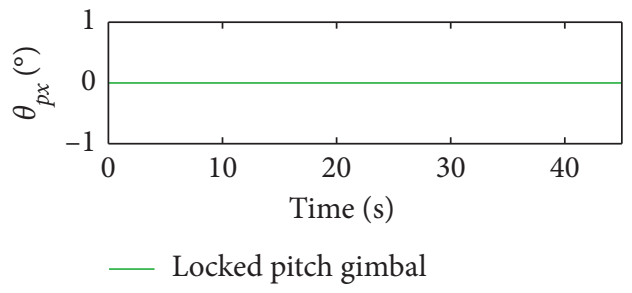

(c)

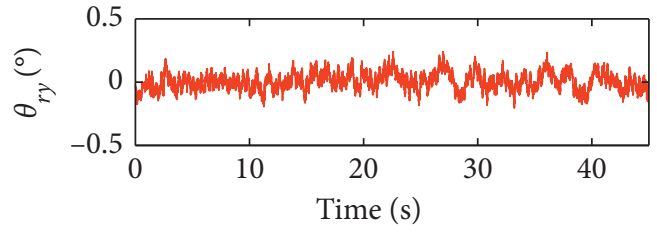

_ Unlocked roll gimbal

(b)

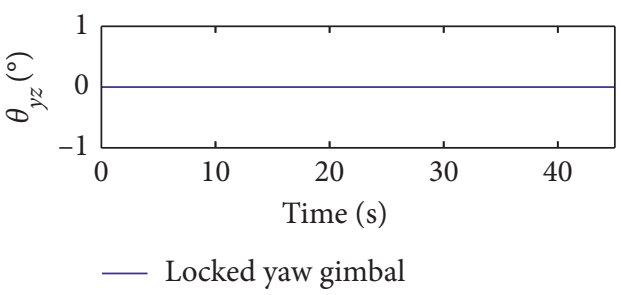

(d)

Figure 14: Angular displacements of (a) base plate, (b) roll gimbal, (c) pitch gimba, and (d) yaw gimbal with single unlocked gimbal.

$0.0693^{\circ}$ because of the disturbance generated by the dynamic base plate. As shown in Figures 14(c) and 14(d), the pitch gimbal and yaw gimbal are kept at the balanced status when they are locked, so the angular displacements of the pitch gimbal and the yaw gimbal are zeros.

3.4.2. Gimbal Coupling of Two Unlocked Gimbals. When only the pitch gimbal is locked, the roll gimbal and the yaw gimbal work at unlocked mode, and they are driven by gimbal motors. With the AMB system of yaw gimbal switched on, the angular displacements of three gimbals are measured and plotted in Figure 15. The angular displacement of roll gimbal is plotted in Figure 15(b), and its RMS is $0.0739^{\circ}$. The blue line in Figure $15(\mathrm{~d})$ is the angular displacement of yaw gimbal, and its RMS is found to be $0.0694^{\circ}$. The RMS of pitch gimbal's angular displacement is greater than that of yaw gimbal. Therefore, this experimental result validates the prediction of better performance on disturbance isolation by using the yaw gimbal suspended by the AMB system than the roll gimbal supported by mechanical bearings.

3.4.3. Gimbal Coupling of Three Unlocked Gimbals. In this experiment, all three gimbals are unlocked and driven by gimbal motors, and the AMB system of yaw gimbal is switched on. The angular displacements of three gimbals are plotted in Figure 16. The RMS of roll gimbal's angular displacement is $0.1349^{\circ}$ in Figure 16(b). The RMS of pitch gimbal's angular displacement is found to be $0.0861^{\circ}$ in Figure 16(c), and the RMS of yaw gimbal's angular displacement is $0.0725^{\circ}$ in Figure 16(d). Compared to the angular displacement of roll gimbal in Figure 15(b), the RMS of roll gimbal's angular displacement increases from $0.0739^{\circ}$ to $0.1349^{\circ}$ in this case. It indicates that the attitude stabilization precision of roll gimbal decreases with the number of unlocked gimbals, so the gimbal coupling effect among three gimbals increases with the number of unlocked gimbals.

3.4.4. Comparison of Gimbal Coupling. The comparison in Table 2 shows that the yaw gimbal suspended by an AMB system has better attitude stabilization precision than the roll gimbal and the pitch gimbal supported by mechanical bearings, so the yaw gimbal with an AMB system has better performance on isolating vibration than the pitch gimbal and the roll gimbal. Moreover, for the roll gimbal, the RMS of angular displacement increases with the number of unlocked gimbals, so the gimbal coupling effect among three gimbals becomes more serious with increasing number of unlocked gimbals. This experimental result matches with analysis results from (13) and (20).

3.5. Cross-Feedback Control for Gimbal Coupling and Base Coupling. This experiment is to validate that the crossfeedback control could effectively suppress the gimbal coupling and the base coupling. In the first test, there is only the gimbal coupling when the base plate of three-axis ISP works at static status; three unlocked gimbals are driven by torque motors with and without the cross-feedback control applied. The angular displacements of the roll gimbal and the yaw gimbal in the two cases are measured. In the second test, the base plate of three-axis ISP works at dynamic status, so the gimbal coupling and the base coupling both exist. Three unlocked gimbals are driven by torque motors to keep them at balanced status with and without cross-feedback control applied. The angular displacements of the roll gimbal and the yaw gimbal in the two cases are measured and compared. 


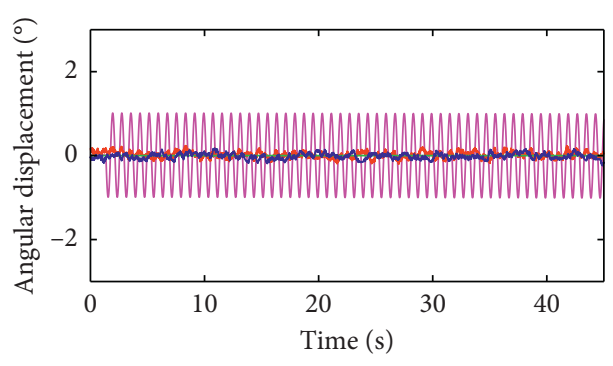

- Base plate

(a)

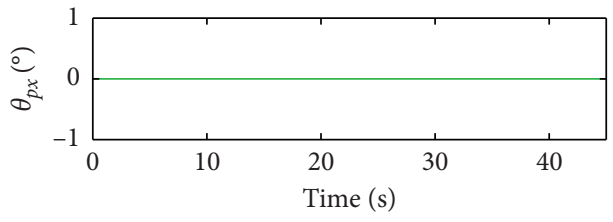

__ Locked pitch gimbal

(c)

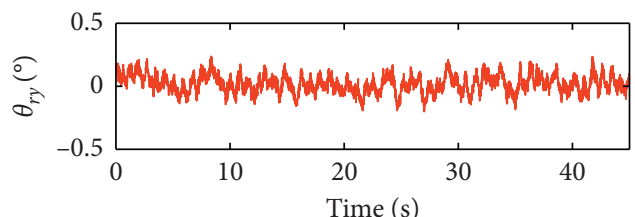

__ Unlocked roll gimbal

(b)

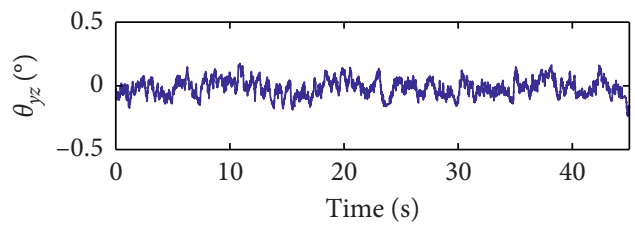

- Unlocked yaw gimbal

(d)

Figure 15: Angular displacements of (a) base plate, (b) roll gimbal, (c) pitch gimbal, and (d) yaw gimbal with two unlocked gimbals.

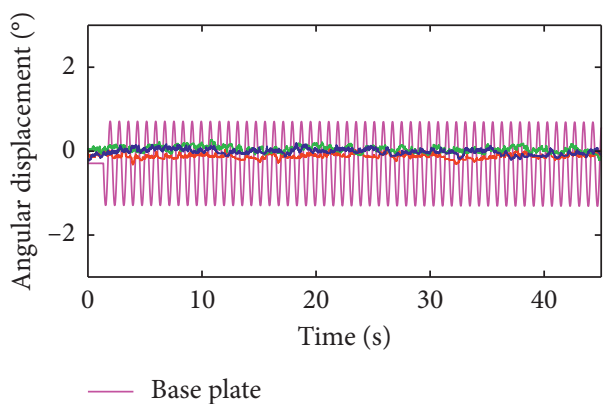

(a)

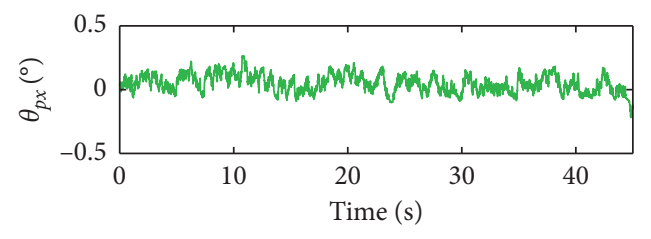

_ Unlocked pitch gimbal

(c)

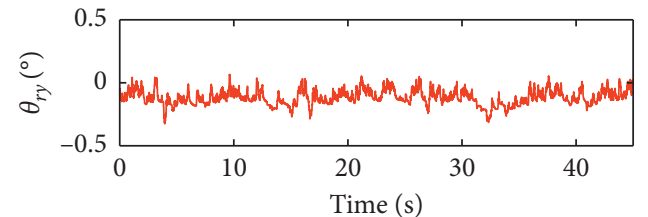

Unlocked roll gimbal

(b)

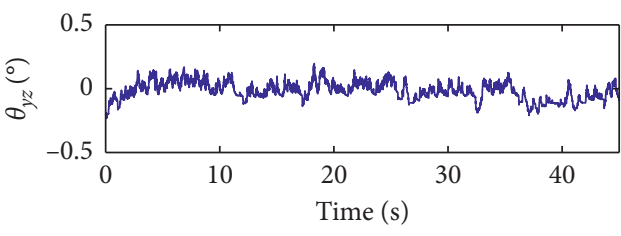

__ Unlocked yaw gimbal

(d)

FIgURE 16: Angular displacements of (a) base plate, (b) roll gimbal, (c) pitch gimbal, and (d) yaw gimbal with three unlocked gimbals.

TABLE 2: Attitude stabilization precision with different numbers of unlocked gimbals.

\begin{tabular}{|c|c|c|c|}
\hline \multirow{2}{*}{$\begin{array}{l}\text { Number of unlocked } \\
\text { gimbals }\end{array}$} & \multicolumn{3}{|c|}{ RMS of angular displacement } \\
\hline & Roll gimbal & Pitch gimbal & Yaw gimbal \\
\hline Single gimbal & $0.0603^{\circ}$ & 0 & 0 \\
\hline Double gimbals & $0.0739^{\circ}$ & 0 & $0.0694^{\circ}$ \\
\hline Triple gimbals & $0.1349^{\circ}$ & $0.0861^{\circ}$ & $0.0725^{\circ}$ \\
\hline
\end{tabular}

3.5.1. Cross-Feedback Control of Gimbals with Static Base Plate. The respective angular displacements of the yaw gimbal and the roll gimbal with and without the crossfeedback control are measured when the base plate of threeaxis ISP is kept static. The red line in Figure 17 is the angular displacement of the roll gimbal, and the blue line is the angular displacement of the yaw gimbal. When the crossfeedback control is used, the RMS of roll gimbal's angular 


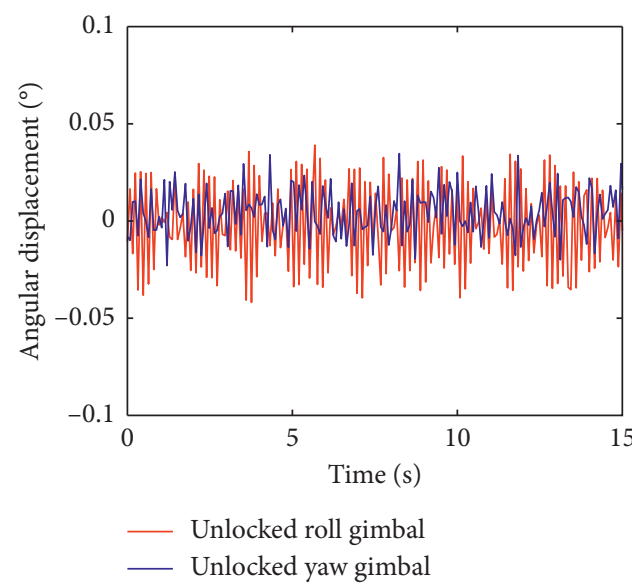

(a)

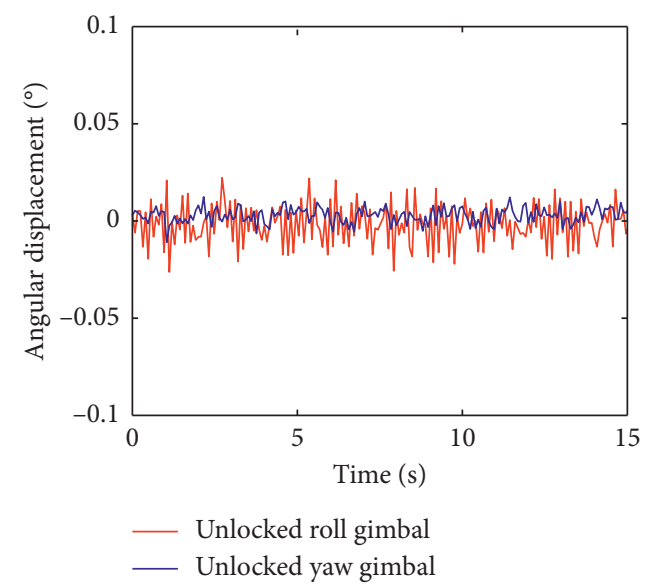

(b)

FIGURE 17: Angular displacements of roll and yaw gimbals with static base plate: (a) without cross-feedback and (b) with cross-feedback.

TABle 3: Attitude stabilization precision of roll and yaw gimbal with static base plate.

\begin{tabular}{lccc}
\hline & Without cross-feedback & With cross-feedback & Reduction \\
\hline RMS of roll gimbal & $0.0229^{\circ}$ & $0.0105^{\circ}$ & 54 \\
RMS of yaw gimbal & $0.0129^{\circ}$ & $0.0049^{\circ}$ & 62 \\
\hline
\end{tabular}

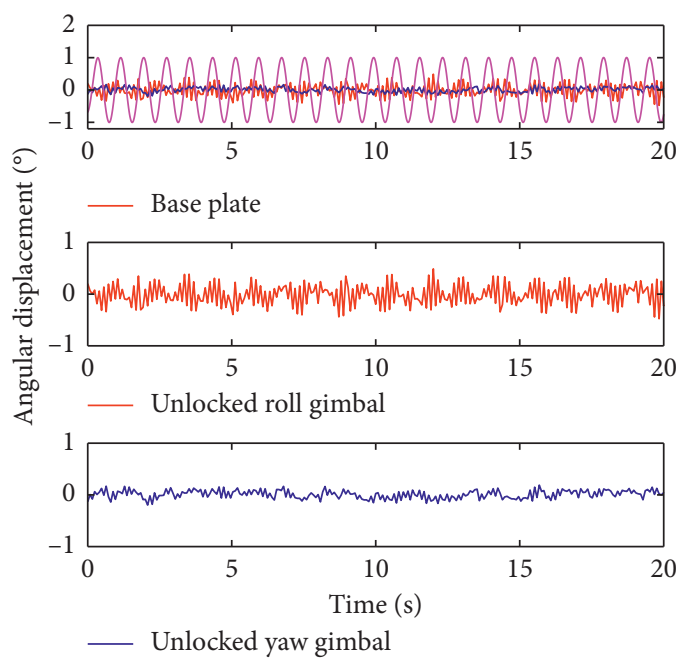

(a)

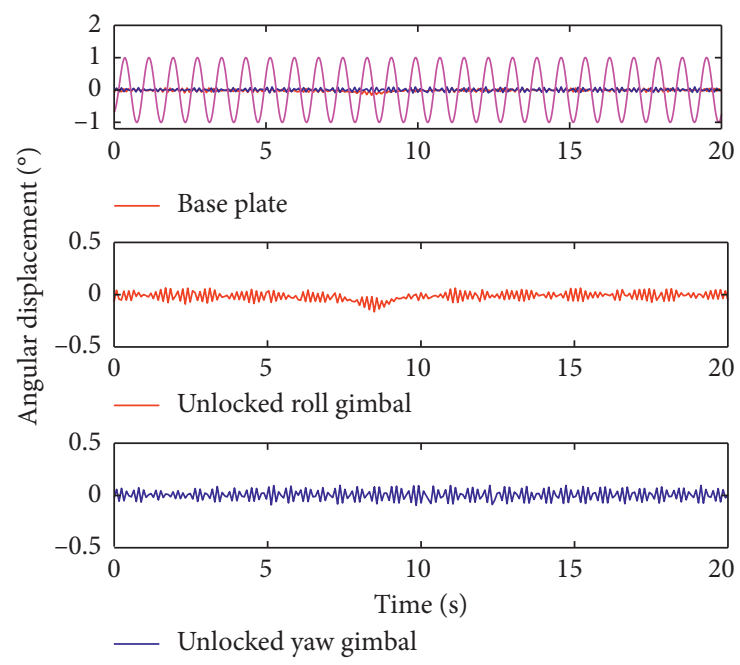

(b)

FIGURE 18: Angular displacements of roll and yaw gimbals with dynamic base plate: (a) without cross-feedback and (b) with cross-feedback.

displacements decreases from $0.0229^{\circ}$ to $0.0105^{\circ}$ in Table 3, and the RMS of yaw gimbal's angular displacements decreases from $0.0129^{\circ}$ to $0.0049^{\circ}$. Therefore, the cross-feedback control is effective in mitigating the gimbal coupling when the base plate works at static status.

\subsubsection{Cross-Feedback Control of Gimbals with Dynamic Base} Plate. The angular displacements of the roll gimbal and the yaw gimbal with the dynamic base plate are plotted in Figure 18 when the cross-feedback control is applied to suppress the coupling effect. The RMS of roll gimbal's angular displacements decreases from $0.2134^{\circ}$ to $0.0526^{\circ}$, and
TABle 4: Attitude stabilization precision of roll and yaw gimbal with dynamic base plate.

\begin{tabular}{lccc}
\hline & $\begin{array}{c}\text { Without cross- } \\
\text { feedback }\end{array}$ & $\begin{array}{c}\text { With cross- } \\
\text { feedback }\end{array}$ & Reduction (\%) \\
\hline $\begin{array}{l}\text { RMS of roll } \\
\text { gimbal }\end{array}$ & $0.2134^{\circ}$ & $0.0526^{\circ}$ & 75 \\
$\begin{array}{l}\text { RMS of yaw } \\
\text { gimbal }\end{array}$ & $0.0828^{\circ}$ & $0.0459^{\circ}$ & 44 \\
\hline
\end{tabular}

the RMS of yaw gimbal's angular displacements decreases from $0.0828^{\circ}$ to $0.0459^{\circ}$ in Table 4 . Therefore, the attitude stabilization precisions of the roll gimbal and the yaw gimbal 
are improved after using the cross-feedback, so it proves that the cross-feedback control can suppress the base coupling effect and the gimbal coupling effect when the base plate works at dynamic status.

\section{Conclusion}

In this article, the complex dynamics of a three-axis ISP with an AMB system are analyzed. By comparing the angular displacements of the roll gimbal with those of the yaw gimbal, the yaw gimbal suspended by an AMB system has better performance on vibration isolation than the roll gimbal supported by mechanical bearing. Therefore, the AMB system could be used in three-axis ISP to provide better attitude stabilization precision to the suspended gimbal, so this structure expands the application range of AMB system.

In addition, the gimbal coupling is firstly proven by comparing angular displacements of different unlocked gimbals in the experiment. The gimbal coupling is intensified with increasing number of unlocked gimbals when the RMS of the roll gimbal's angular displacement increases from $0.0603^{\circ}$ to $0.1349^{\circ}$. The base coupling effect with dynamic base plate is more serious than that with static base plate.

Finally, a cross-feedback control scheme is designed to mitigate the gimbal coupling and the base coupling. Experimental results demonstrate that the cross-feedback control scheme is useful to mitigate both the gimbal coupling and the base coupling. For the static base plate, the RMS of yaw gimbal's angular displacements decreases from $0.0129^{\circ}$ to $0.0049^{\circ}$ with applying cross-feedback control. For the dynamic base plate, the RMS of yaw gimbal's angular displacements decreases from $0.0828^{\circ}$ to $0.0459^{\circ}$.

\section{Data Availability}

The data used to support the findings of this study are available from the corresponding author upon request.

\section{Conflicts of Interest}

The authors declare that they have no conflicts of interest.

\section{References}

[1] Z. Hurak and M. Rezac, "Image-based pointing and tracking for inertially stabilized airborne camera platform," IEEE Transactions on Control Systems Technology, vol. 20, no. 5, pp. 1146-1159, 2012.

[2] J.-H. Moon and S. Y. Jung, "Implementation of an image stabilization system for a small digital camera," IEEE Transactions on Consumer Electronics, vol. 54, no. 2, 2008.

[3] J. Hilkert, "Inertially stabilized platform technology concepts and principles," IEEE Control Systems, vol. 28, no. 1, pp. 26-46, 2008.

[4] M. F. Reis, G. P. Carvalho, A. F. Neves, and A. J. Peixoto, "Dynamic model and line of sight control of a 3-DOF inertial stabilization platform via feedback linearization," in Proceedings of the 2018 Annual American Control Conference
(ACC), pp. 1313-1318, IEEE, Milwaukee, WI, USA, August 2018.

[5] H. F. Mokbel, L. Q. Ying, A. A. Roshdy, and C. G. Hua, "Modeling and optimization of electro-optical dual axis inertially stabilized platform," in Proceedings of the International Conference on, 2012 Optoelectronics and Microelectronics (ICOM), pp. 372-377, IEEE, Changchun, China, August 2012.

[6] P. J. Kennedy and R. L. Kennedy, "Direct versus indirect line of sight (LOS) stabilization," IEEE Transactions on Control Systems Technology, vol. 11, no. 1, pp. 3-15, 2003.

[7] J. Hilkert and B. Pautler, "A reduced-order disturbance observer applied to inertially stabilized line-of-sight control," in Acquisition, Tracking, Pointing, and Laser Systems Technologies XXV, vol. 8052 , p. $80520 \mathrm{H}$, International Society for Optics and Photonics, Bellingham, WA, USA, 2011.

[8] X. Zhou, H. Zhang, and R. Yu, "Decoupling control for twoaxis inertially stabilized platform based on an inverse system and internal model control," Mechatronics, vol. 24, no. 8, pp. 1203-1213, 2014.

[9] A. Safa and R. Y. Abdolmalaki, "Robust output feedback tracking control for inertially stabilized platforms with matched and unmatched uncertainties," IEEE Transactions on Control Systems Technology, vol. 27, no. 1, pp. 118-131, 2017.

[10] Z. Hurák and M. Rezáč, "Control design for image tracking with an inertially stabilized airborne camera platform," in Proceedings of the Automatic Target Recognition XX; Acquisition, Tracking, Pointing, and Laser Systems Technologies XXIV; and Optical Pattern Recognition XXI, vol. vol. 7696, p. 76961H, April 2010.

[11] D. Rajesh, A. Praveen, and M. R. Pasumarthi, "Design and analysis of two-Axis seeker stabilization system," in Proceedings of the International Conference on Modern Research in Aerospace Engineering, Springer, Singapore, Singapore, pp. 97-107, February 2018.

[12] Y. Zhang, S. Liu, Y. Xiong, C. Li, and M. Li, "Stabilization loop modeling of three-axis inertial stabilized platform with a new gyro installing mode," in Proceedings of the IEEE Chinese Guidance, Navigation and Control Conference (CGNCC), pp. 240-245, IEEE, Yantai, China, August 2014.

[13] S. Li, M. Zhong, and Y. Zhao, "Accelerometer error estimation and compensation for three-axis gyro-stabilized camera mount based on proportional multiple-integral observer," Science China Technological Sciences, vol. 57, no. 12, pp. 2387-2395, 2014.

[14] F. Königseder, W. Kemmetmüller, and A. Kugi, "Attitude control strategy for a camera stabilization platform," Mechatronics, vol. 46, pp. 60-69, 2017.

[15] Z. Lin and K. Liu, "Inertially stabilized line-of-sight control system using a magnetic bearing with vernier gimbaling capacity," in Optical Design and Testing VI, vol. vol. 9272, p. 92720Q, International Society for Optics and Photonics, Bellingham, WA, USA, 2014.

[16] J. Fang, C. Wang, and T. Wen, "Design and optimization of a radial hybrid magnetic bearing with separate poles for magnetically suspended inertially stabilized platform," IEEE Transactions on Magnetics, vol. 50, no. 5, pp. 1-11, 2014.

[17] Q. Mu, G. Liu, and X. Lei, “A RBFNN-based adaptive disturbance compensation approach applied to magnetic suspension inertially stabilized platform," Mathematical Problems in Engineering, vol. 2014, pp. 1-9, 2014.

[18] W. Tong, B. Xiang, and W. Wong, "Gimbal torque and coupling torque of six degrees of freedom magnetically 
suspended yaw gimbal," International Journal of Mechanical Sciences, vol. 168, 2020.

[19] J. Tang, B. Xiang, and Y. Zhang, "Dynamic characteristics of the rotor in a magnetically suspended control moment gyroscope with active magnetic bearing and passive magnetic bearing," ISA Transactions, vol. 53, no. 4, pp. 1357-1365, 2014.

[20] B. Xiang and J. Tang, "Suspension and titling of verniergimballing magnetically suspended flywheel with conical magnetic bearing and Lorentz magnetic bearing," Mechatronics, vol. 28, pp. 46-54, 2015.

[21] L. Zhuchong, L. Kun, and Z. Wei, "Inertially stabilized platform for airborne remote sensing using magnetic bearings," IEEE/ASME Transactions on Mechatronics, vol. 21, no. 1, pp. 288-301, 2016.

[22] M. Ahrens, L. Kucera, and R. Larsonneur, "Performance of a magnetically suspended flywheel energy storage device," IEEE Transactions on Control Systems Technology, vol. 4, no. 5, pp. 494-502, 1996.

[23] X. Yao and Z. Chen, "Sliding mode control with deep learning method for rotor trajectory control of active magnetic bearing system," Transactions of the Institute of Measurement and Control, vol. 41, no. 5, pp. 1383-1394, 2019.

[24] B. Xiang and W. Wong, "Electromagnetic vibration absorber for torsional vibration in high speed rotational machine," Mechanical Systems and Signal Processing, vol. 140, 2020.

[25] Y.-S. Zhang, R.-Y. Zhu, and J.-C. Fang, "Analysis on dynamics coupling of inertial stabilized platform for aerial remote sensing," Journal of Chinese Inertial Technology, vol. 5, 2011.

[26] H. Liao, Y. Lu, S. Fan, and D. Fan, "Dynamics analysis and decoupling control for a differential cable drive inertially stabilized platform," Proceedings of the Institution of $\mathrm{Me}$ chanical Engineers, Part I: Journal of Systems and Control Engineering, vol. 229, no. 7, pp. 652-661, 2015.

[27] X. Zhou, G. Gong, J. Li, H. Zhang, and R. Yu, "Decoupling control for a three-axis inertially stabilized platform used for aerial remote sensing," Transactions of the Institute of Measurement and Control, vol. 37, no. 9, pp. 1135-1145, 2015.

[28] J. Fang, R. Yin, and X. Lei, "An adaptive decoupling control for three-axis gyro stabilized platform based on neural networks," Mechatronics, vol. 27, pp. 38-46, 2015.

[29] J. Mao, J. Yang, Q. Li, and S. Li, "Extended-state-observerbased output feedback sliding mode control of inertial stabilized platform," in Proceedings of the IEEE Conference onIndustrial Electronics and Applications (ICIEA), pp. 15281533, IEEE, Siem Reap, Cambodia, February 2017.

[30] F. Dong, X. Lei, and W. Chou, "A dynamic model and control method for a two-axis inertially stabilized platform," IEEE Transactions on Industrial Electronics, vol. 64, no. 1, pp. 432-439, 2016.

[31] X. Zhou, C. Yang, and T. Cai, "A model reference adaptive control/PID compound scheme on disturbance rejection for an aerial inertially stabilized platform," Journal of Sensors, vol. 2016, pp. 1-11, 2016.

[32] F. Wang, R. Wang, E. Liu, and W. Zhang, "Stabilization control mothed for two-Axis inertially stabilized platform based on active disturbance rejection control with noise reduction disturbance observer," IEEE Access, vol. 7, pp. 99521-99529, 2019.

[33] J. Mao, J. Yang, X. Liu, S. Li, and Q. Li, "Modeling and robust continuous TSM control for an inertially stabilized platform with couplings," IEEE Transactions on Control Systems Technology, pp. 1-8, 2019.

[34] J. Mao, S. Li, Q. Li, and J. Yang, "Design and implementation of continuous finite-time sliding mode control for 2-DOF inertially stabilized platform subject to multiple disturbances," ISA Transactions, vol. 84, pp. 214-224, 2019.

[35] X. Zhou, Y. Shi, L. Li, R. Yu, and L. Zhao, "A high precision compound control scheme based on non-singular terminal sliding mode and extended state observer for an aerial inertially stabilized platform," International Journal of Control, Automation and Systems, vol. 18, no. 6, pp. 1498-1509, 2020.

[36] B. Xiang and W. O. Wong, "Vibration characteristics analysis of magnetically suspended rotor in flywheel energy storage system," Journal of Sound and Vibration, vol. 444, pp. 235247, 2019. 